\title{
LAS INDUSTRIAS DERIVADAS DE LA PESCA EN LA PROVINCIA ROMANA DE LA BÉTICA: LA ALFARERÍA DE “EL RINCONCILLO" (ALGECIRAS, CÁDIZ)
}

\author{
FISHING INDUSTRIES IN THE ROMAN PROVINCE OF BAETICA. \\ THE “EL RINCONCILLO” KILN (ALGECIRAS, CÁDIZ)
}

por

\author{
SILVIA FERNÁNDEZ CACHO
}

RESUMEN En este trabajo se presenta una panorámica general del papel fundamental que tuvieron las industrias derivadas de la pesca en la Bética romana, focalizando los análisis de detalle en la Bahía de Algeciras, donde estas industrias fueron el principal motor de desarrollo económico en la Antigüedad, a través de la realización de una excavación de urgencia realizada a finales de 1991 en el yacimiento de "El Rinconcillo" (Algeciras, Cádiz) y de la que se presentan sus principales conclusiones.

ABSTRACT This paper presents a general overview of the role played by fish industries within the economy of the Betica Roman province. Departing from the data recorded in a rescue excavation carried out in the site of "El Rinconcillo" (Algeciras, Cádiz) in 1991, the analysis focuses on the Bay of Algeciras area, where these industries became a source of economic development during the Antiquity.

\section{LAS INDUSTRIAS DERIVADAS DE LA PESCA EN EL CONTEXTO DE LA ECONOMÍA DE LA BÉTICA ROMANA}

A pesar de la abundante información arqueológica que atestigua la importancia del sector pesquero, la historiografía le ha reservado tradicionalmente un papel de segundo orden, mientras que se otorga una mayor atención al desempeñado por el sector agropecuario dentro del esquema general de la economía de la Bética romana.

Las actividades económicas relacionadas con este sector productivo son muy destacadas en el marco de la economía de época romana, pero no se debe olvidar que en las zonas costeras del sur de Hispania, especialmente en aquellas que no presentan condiciones favorables para el cultivo, el papel desempeñado por las industrias derivadas del sector pesquero cobra la misma o mayor relevancia que la de aquel. 
El problema de lo que podría denominarse "infravaloración" de las actividades artesanales/industriales en la antigüedad se presenta fundamentalmente como consecuencia de tres factores que pueden resumirse en:

1.- La actitud del Historiador de la Antigüedad que ha empleado tradicionalmente como base para el estudio de la economía de la antiguiedad clásica las fuentes literarias. Los datos susceptibles de ser analizados en referencia al sector pesquero e industrias derivadas son fundamentalmente arqueológicos, y como tales, generalmente no han sido objeto de un amplio análisis ${ }^{~}$ ni por parte de los historiadores de la antigüedad, más interesados en estudios basados en aproximaciones epigráfico-literarias, ni por los arqueólogos clásicos, que a menudo tienden a continuar una línea de investigación que se aproxima más a una Historia del Arte Antiguo que a una verdadera Arqueología Clásica (Snodgrass 1985; Dyson 1989 y 1993).

El problema no deriva, pues, de la inexistencia de los datos, sino del hecho de que al no contar ni con un abundante material literario o epigráfico que refleje algo más que las "facetas laudatorias de la realidad productiva de occidente" (Arteaga 1985: 211), ni de restos materiales de considerable valor estético, el estudio de uno de los principales sectores productivos de la Bética romana ha quedado relegado a un segundo término (Fernández-García 1995).

\section{2.- Tendenciosidad con que los mismos historiadores clásicos afrontan el estudio de su propia} economía. La actitud negativa que hacia las actividades manufactureras/industriales y comerciales subyace en las fuentes literarias clásicas -actitud en absoluto extraña teniendo en cuenta el segmento social del que habitualmente proceden- se ha hecho extensiva al conjunto de la población, afianzándose la consideración de que la obtención de plusvalías derivadas de la industria y el comercio era repudiable por la sociedad ${ }^{2}$. Esta tendenciosidad se expresa en los limitados casos en los que se aborda cualquier tipo de análisis de la economía de la época, ya que incluso el hecho económico, en relación al político-militar, poseía una baja consideración moral (Musti 1984), aún cuando parece demostrado que miembros de la élite romana, ya sea directamente ${ }^{3}$ o a través de personas dependientes, participaban en una u otra medida de los beneficios generados por las actividades relacionadas con el comercio (Pavis d'Escurac 1977; Syme 1977). De este modo, cualquier forma de obtención de recursos distinta de los derivados de la tierra no otorgaba el prestigio social de estos últimos, y en algunos casos, especialmente cuando se trata de actividades comerciales y manufactureras de pequeña envergadura, eran incluso censurados (Gabba 1980). Así pues, al escribir para unas clases superiores en recursos y prestigio que despreciaban el comercio, los escritores latinos hicieron escasa mención de las actividades relacionadas con la pesca, y con el resto de manufacturas, y el comercio, mientras que para las agrícolas se han conservado verdaderos "tratados" (Firpo 1980; Valencia 1991).

1. Excepción hecha de los estudios parciales referidos a factorías de salazón o alfares aislados, destacan las aproximaciones generales ofrecidas por M. Tarradell y M. Ponsich (Ponsich-Tarradell 1965; Ponsich 1988) y R.I. Curtis (1979)

2. Existen, no obstante, noticias que muestran como algunos comerciantes reflejan con orgullo en sus inscripciones sepulcrales su vinculación al negotio relacionado con la salazón y salsas de pescado, como sería el caso de Publius Clodius Athenio (negotians salsarius), Tiberius Claudio Docimus (negotians salsamentarius et vinarius) o Marcus Primus Secundianus (negotians muriarius) (Curtis 1979)

3. Véase como ejemplo el caso de los TT. Mamilii miembros de la élite municipal de Tritium Magallum cuya riqueza se generó a través de la producción y el comercio de cerámica sigillata, a pesar de que las interpretaciones de los investigadores difieren a la hora de evaluar la posible repercusión negativa que pudieron tener estas actividades económicas en la promoción social y política de esta familia (Haley 1988; Espinosa 1988). 


\begin{abstract}
3.- La 'industria' y el artesanado se han venido considerando tradicionalmente como actividades económicas dependientes en una u otra medida de la agricultura. J. P. Morel, ha estudiado recientemente esta realidad proponiendo que
\end{abstract}

"il existe des domaines où la manufacture est séparée de l'agriculture pour ainsi dire par définition (...). Laissons de côté la céramique (...) et pensons d'une part aux metaux, au verre, aux colorants, d'autre part au garum, à propos duquel Lepore a pu parler de 'formazione di gruppi indipendenti dall'agricoltura"' (Morel 1985: 90).

Una postura semejante es la sostenida por G. Pucci, cuando analiza el carácter de las ciudades en época romana desde un punto de vista económico. Para él existe

"una riluttanza ad ammetere che manifatture e commerci, per quanto grande fosse la loro scala, generavano ricchezza in maniera autonoma rispetto alla rendita fondiaria e agli altri settori primari della produzione" (Pucci 1985: 276).

Por otro lado, si bien se puede constatar la existencia de una posible dependencia de algunas manufacturas con respecto a los grandes propietarios de tierra, Morel expone la posibilidad de que esta relación de dependencia se pudiera establecer igualmente, y en determinados casos, en sentido contrario (Morel 1985).

A este respecto, P. Silliers (Silliers 1988), refiriéndose a las ciudades de la orilla norte del Estrecho de Gibraltar, plantea y defiende la posibilidad de que sus "evergetas" sean grandes propietarios de tierra más que comerciantes o "industriales" del pescado. Esta hipótesis, al menos por el momento, no ha sido demostrada pero, en el caso de ser considerada como válida, también podría ser el resultado de la inversión de capitales en tierras por parte de los grandes comerciantes o industriales del pescado. La diferencia en el prestigio social que comportaba la realización de ambas actividades hace plausible la hipótesis de que los grandes mercaderes e industriales invirtieran sus beneficios en unas tierras que les proporcionarían el reconocimiento de las elites que su profesión, aunque quizá más rentable, no les facilitaba (Rostovtzeff 1981: 284). En este caso la relación de dependencia agricultura-manufactura, se realizaría a la inversa: la primera quedaría sujeta al rendimiento de la segunda. Además, la falta de terreno apropiado para el cultivo en la zona hace pensar en que dichas propiedades, en el caso de existir, se volcarían hacia la explotación de recursos ganaderos, menos rentables pero otorgadores de más prestigio a estas clases privilegiadas.

Por lo que se refiere al proceso de producción de los contenedores destinados a transportar los productos derivados del pescado, podría considerarse como actividad económica que se desarrolla de manera totalmente autónoma del trabajo agrícola (Carandini 1981: 257).

Según el estudio de J. P. Morel sobre las relaciones comerciales en el occidente griego, se pueden distinguir dos grados en el fenómeno de aculturación que nace a través de los contactos comerciales: el primero sería el desplazamiento de los profesionales y el segundo la imitación, que en el caso de los "vasos contenedores" permiten suponer la transferencia de producciones y técnicas agrícolas (Morel 1983). En el siglo I d.n.e., esta situación esta prácticamente superada en la Bética romana. En este sentido, a partir de Augusto, comienzan a producirse tipos anfóricos específicos de esta provincia, pasando de la imitación de formas a la producción de otras propias, no sólo en cuanto se refiere a las 
ánforas de salazón, sino también a las vinarias y olearias ${ }^{4}$, lo cual sugiere la progresiva independencia económica de la misma con respecto a Roma ${ }^{5}$

Así pues, antes de que terminara la hegemonía comercial de Roma con la llegada del Imperio, por la competencia económica ejercida por las provincias con respecto a la península itálica y la pérdida de privilegios económicos de esta última (Carandini 1989), Hispania exportaba, junto con los metales, una cantidad importante y creciente de salazón y salsas de pescado (Lamboglia 1974) y ya a partir de la época de Augusto se puede asegurar que estas exportaciones se colocan a la cabeza de entre las realizadas desde la Bética (Zevi 1966; Chic 1985; 1989; 1994).

La importancia del comercio de estos productos, como último eslabón de la cadena de producción, se ve reflejada en el volumen de ánforas especialmente dedicadas a este transporte en comparación con el resto de los tipos destinados a contener otros alimentos como el aceite y el vino. Como muestra se puede evaluar cuantitativamente la presencia de estos contenedores en varios yacimientos arqueológicos ${ }^{6}$ (en aquellos casos en los que se ofrecen datos cuantificables o cuantificados por los excavadores) de la Península Itálica, punto de destino más importante, junto con los campamentos de legionarios, de los cargamentos procedentes de la provincia romana de la Bética, de diversas características tanto en relación con su situación geográfica como por su tipología y funcionalidad específicas.

Las campañas de excavaciones que tuvieron lugar en Luni (Colonia Lunensis) entre los años 1972-1974 (Lusuardi 1977a; 1977b), proporcionaron un gran número de ánforas de origen hispánico, lo cual prueba el activo comercio entre Hispania e Italia durante toda la edad imperial con especial auge a lo largo del s. I d.n.e.. Individualizando estas ánforas hispánicas del resto de los tipos de diverso origen y tomando la totalidad del arco cronológico registrado en este yacimiento (177 a.n.e.- $\mathrm{s} . \mathrm{V}$ d.n.e.), en términos absolutos se documentan: dieciséis fragmentos de ánforas del tipo 2-4 de Dressel de imitación hispánica (de entre los cuales un número elevado pero no precisado son de origen bético), cuarenta y cuatro fragmentos del tipo Dressel 20, seis de Haltern 70, cincuenta y uno de Dressel 7-13 y derivadas, once de Pelichet 46, seis bordes de Dressel $14 \mathrm{y}$ otros quince fragmentos de ánforas afines a este último tipo. Proporcionalmente pues, las ánforas de salazón y salsas de pescado ocupan el primer lugar en número de fragmentos anfóricos recuperados, documentándose el elevado índice de comercialización de este tipo de productos en relación con el resto de los exportados desde Hispania, que alcanza su máximo apogeo a mediados del siglo I, cuando eran transportados en las ánforas Dressel 7-13, si bien tipos afines a la Dressel 14 se han documentado en contextos de hasta el s.V d.n.e. con carácter residual (Tabla 1).

Las importaciones de salazón bético en Luni superan incluso a las de aceite cuando estas ya se habían afirmado en el mercado itálico. En este yacimiento, las ánforas de salazón, que según los estudios mineralógicos realizados proceden en su mayor parte de la Bética, sólo son superadas en términos absolutos por las Dressel 1 y las Dressel 2-4, ambas de origen itálico.

En Pompeya, son también las ánforas de salazón las que ocupan cuantitativamente el primer puesto entre las ánforas de producción hispánica, siendo los tipos Pelichet 46 y Beltrán IIB los más representativos,

4. Como aproximación al análisis de los cambios en la producción en relación con los procesos de aculturación (Almagro 1983).

5. Para esta época N. Lamboglia habla ya de una independencia económica de Hispania con respecto a Roma. Esta independencia se manifiesta en la elaboración de "una economía y una produçción autosuficiente y capaz de competir con el mercado itálico" (Lamboglia 1974).

6. Aunque los datos obtenidos no se refieren al volumen total contenido en las ánforas, la diferencia entre los hallazgos es tan significativa que aunque se desplazaran en alguna medida a la baja en el caso de la salazón resultarían prácticamente igual de representativos. 
seguidos a cierta distancia por las ánforas Dressel 7-11 (Manacorda 1977). Las Dressel 20 son, por otra parte, muy poco significativas a diferencia de lo que ocurre en Ostia?

En las excavaciones realizadas en las Termas del Nadador en Ostia (Carandini-Fabriccotti-PalmaPucci-Semeraro 1973), se constatan también con un indice de presencia bastante alto las ánforas del tipo Dressel 7-11 en relación con los otros tipos de ánforas y, en menor número, las Beltran IIB y las Pelichet 46. Las del primer tipo alcanzan su mayor apogeo en edad Julio-Claudia, si bien están documentadas ampliamente durante todo el s.I d.n.e.

Clementina Panella (Panella 1981), sistematiza toda la información referida a los restos de ánforas recuperados durante las excavaciones realizadas en Ostia mostrando un cuadro evolutivo de los diferentes tipos desde la república tardía a la edad antonina. En ningún momento las importaciones de salazón bético fueron superadas por el vino o el aceite.

Especial interés merecen los datos aportados por el hallazgo del depósito de La Longarina estudiado por A. Hesnard (Hesnard 1980). En este depósito se ha constatado la presencia de ánforas para el transporte de vino, aceite y productos derivados del pescado. De las ánforas de aceite seis provienen de la Bética, tres de Brindis y 4 de Tripolitania: un total de 13 envases de diversa procedencia. De las ánforas vinarias cincuenta proceden de la Campania meridional, cinco de la Campania del norte y el sur del Lacio, una de Apulia-Calabria, tres de la Italia del Norte, cuatro de Cos, ocho de Rodas, veintiséis de la Tarraconense y treinta y dos de la Bética. Un total pues de ciento veintinueve ánforas de procedencia hispánica, itálica y griega. Por último, en cuanto se refiere a las ánforas de garum y salazón de pescado, se atestigua la presencia de ciento cuatro envases, de entre los cuales ciento tres son con seguridad de procedencia Bética.

Se refleja así claramente cómo son los productos de la Bética los más representados en el conjunto del depósito y, entre ellos, con abrumadora distancia, los derivados del pescado, que constituye el mayor volumen de un mismo producto y origen de los documentados en el depósito (Tabla 1).

Especial interés, por el minucioso estudio realizado, merecen los datos obtenidos de la cuantificación comparativa de los restos de ánforas de distintos tipos y procedencias registrados durante las excavaciones de la Villa de Settefinestre (Carandini 1985), donde se observa que la presencia de ánforas de salazón hispánicas sólo es superada en términos absolutos, como ocurría en Luni, por las Dressel 2-4 itálicas. Si son consideradas sólo las producciones hispanas, las ánforas de salazón quintuplican y cuadriplican respectivamente a las de aceite y vino en el periodo comprendido entre la época de Trajano y la edad Antonina tardía. La diferencia sigue siendo significativa para el tercer periodo de ocupación de la villa, datado en edad severiana.

Los hallazgos submarinos ofrecen la misma tendencia. En 1980 R. Pascual Guach (Pascual 1980) publicó un estudio estadístico de los cargamentos de barcos hundidos en el Mediterráneo Occidental, que transportaban mercancías que total o parcialmente provenían de la Bética. A pesar de que el azar en el caso de los hundimientos puede jugar un papel importante y de que no se explicitan los datos cuantificados, este trabajo resulta interesante por el método empleado que, a pesar de los márgenes de error que pueda tener, deja clara constancia de cómo los cargamentos de origen bético destacaban sobre los demás en una proporción que llegó a ser del $100 \%$ en la primera mitad del s. II d.n.e.. Tomando un arco cronológico que se extiende desde el 50 a.C. al 250 d.C. la proporción de productos transportados

7. "Le correnti commerciali tra penisola iberica e Campania, nel momento della distruzione dei centri vesuviani, risulta evidentemente attive e probablimente stabili; queste riguarda però essenzialmente il meridione della penisola iberica, la Betica, e si incentrano sul commercio dei derivati del pesce (...). L'importazione dell'olio betico risulta invece se non marginale, certo esigua: l'olio campano e di Venafro insieme a quello tripolitano, doveva ancora soddisfare intorno alla metá del I secolo d.C. gran parte del fabbisogno locale" (Manacorda 1977: 131). 
(el autor no tiene en cuenta el vino y sí los metales) las ánforas de salazón destacarían claramente (66\%) de las olearias $(26.5 \%)$ y los metales $(7.5 \%)$ (Tabla 1$)$.

Por periodos cronológicos el gráfico indica una supremacía de la exportación de salazón frente a las de aceite hasta la segunda mitad del siglo II d.n.e., siendo este último producto el único exportado en la primera mitad del s. III d.n.e.. Es interesante anotar que esta última observación se ha establecido en base al estudio de un solo naufragio por lo que el mismo autor lo incluye a título ilustrativo.

Como ejemplos concretos destacan los datos proporcionados por el estudio de los materiales de dos pecios, ambos de mediados del s. I d.n.e.: Lavezzi I (Liou 1990) y Lavezzi 2 (Liou-Domergue 1990).

En el primero se ha localizado un cargamento de ánforas de aceite, vino y salazón proveniente de la Bética, así como un reducido número de lingotes de cobre y plomo y de cerámica común. El material no está estudiado en su totalidad ya que el pecio ha sufrido excavaciones no controladas así como numerosas sustracciones clandestinas, por lo que se realizó a través del material depositado en el Museo de Bastia y las publicaciones de Bebko, que dirigió cuatro campañas de excavaciones en los años 60 . Entre las ánforas recuperadas se registran cinco ejemplares de ánforas olearias Dressel 20, quince vinarias Haltern 70, dos Dressel 28 y cuatro Dressel 2-4 (estas últimas probablemente de la Tarraconense según el autor). En cuanto a las ánforas de salazones y salsa de pescado se han localizado diez ejemplares del tipo Dressel 38, treinta y dos Dressel 14, catorce Dressel 9, una Dressel 8 y otra Dressel 7; un total de cincuenta y ocho ejemplares. Calculando las porcentuales del cargamento las ánforas de salazón ocuparían el primer lugar de los envases transportados con un $69 \%$ del total, frente al $6 \%$ de las olearias y el $25 \%$ de las vinarias (Tabla 1 ).

Más abrumadora todavía es la diferencia existente entre el número de ánforas que representan los diversos tipos en el pecio Lavezzi 2, excavado de 1978 a 1981 y datado entre los años 20-30 d. C.. De un total de doscientas once ánforas recuperadas veintiséis son olearias (Dressel 20), treinta y tres de vino (treinta Haltern 70 y tres Dressel 28?) y ciento cincuenta y dos de salazón (diecisiete Dressel 8, veintitrés Dressel 9 y ciento doce entre Dressel 7-11 y Pompeya VII). Los porcentajes reflejan la misma tendencia ${ }^{8}$, con un ligero ascenso del porcentaje de ánforas de salazón transportadas (72\%) (Tabla 1).

TABLA 1*

\begin{tabular}{|l|c|c|c|c|c|}
\cline { 2 - 6 } \multicolumn{1}{c|}{} & Luni & La Longarina & Pecios & Lavezzi 1 & Lavezzi 2 \\
\hline Anf. olearias & 29,5 & 4,2 & 26,5 & 6,0 & 12,3 \\
\hline Anf. vinarias & 14,7 & 22,7 & - & 25,0 & 15,6 \\
\hline Anf. salazón & 55,7 & 73,0 & 75,0 & 69,0 & 72,0 \\
\hline Metales & - & - & 75,0 & - & - \\
\hline
\end{tabular}

* Datos porcentuales

Se constata pues claramente el papel destacado de las industrias derivadas de la pesca y su importancia cuantitativa en el panorama general de las exportaciones realizadas desde el sur de Hispania.

8. El elevado porcentaje de ánforas de salazones puede ser debido, según B. Liou y C. Domergue, a que por su ubicación en el barco que las trasportaba (zona central), han sufrido en menor grado los efectos del expolio a que el pecio ha estado sometido durante años. No obstante, piensan que en ningún caso representaban menos de la mitad del cargamento, decantándose por estimar un volumen situado entre la mitad y los 2/3 del total del mismo (Liou-Domergue 1990). 
Estas industrias, dedicadas a la transformación del pescado y a la fabricación de ánforas para su transporte, han dejado en las costas béticas, sobre todo occidentales, innumerables restos arqueológicos, evidenciándose la existencia de grandes centros manufactureros, como el de Baelo Claudia, Carteya o Cádiz en la fabricación de salazón y salsas de pescado o el Puerto de Santa María y Puerto Real en la de los contenedores.

En el área del Estrecho de Gibraltar las evidencias arqueológicas que prueban la importancia de estas industrias, son muy numerosas. Las factorías de salazón y los alfares relacionados directamente con la fabricación de envases para su transporte, jalonan sus costas, concentrádose especialmente en la provincia de Cádiz (Ponsich 1988). No es extraño inducir a partir de este hecho el carácter primordial de este sector productivo que, aunque ya existente en épocas anteriores, se multiplica tras los primeros años de las conquista romana.

La riqueza natural de las aguas del Estrecho de Gibraltar pudo ser además, como apuntan algunos investigadores, motor del proceso de colonización en la región tanto en época protohistórica (Morales-Roselló 1988; Muñoz-de Frutos-Berriatua 1988), como romana (Arteaga 1985). La fácil implantación económica de Roma en los centros púnicos peninsulares se basaría en las comunicaciones marítimas que

“...iban a potenciar sin duda las posibilidades de los comerciantes, armadores de barcos, navegantes y demás sectores organizados en los menesteres del mar, de modo que tampoco iba a ser problemática la citada conciliación, por tratarse de centros costeros y, en consecuencia, con unas ventajas geopolíticas inmejorables." (Arteaga 1985: 210)

La situación que se constata en el Campo de Gibraltar no es pues una excepción dentro del panorama general, habiéndose documentado hasta la fecha factorías de salazón como las de Carteia (San Roque), Algeciras, Getares II (Algeciras), Mellaria (Tarifa) o Baelo Claudia (Tarifa) y alfares para la producción de ánforas como los de la Calle Aurora de Campamento (San Roque) o El Rinconcillo (Algeciras). El clima de la zona, no demasiado apropiado para el cultivo de determinados productos como los cereales o el olivo y la escasa potencialidad agrícola de su suelo, induce a pensar que la pesca y las industrias derivadas de la misma se convirtieron en la actividad económica básica de la zona.

En este contexto, el estudio concreto del alfar de 'El Rinconcillo' puede aportar nueva documentación sobre este tema, sirviendo de indicador del carácter y la evolución de la economía a finales de la república y alto imperio en el Campo de Gibraltar (Fernández 1994).

\section{LA ALFARERÍA ROMANA DE 'EL RINCONCILLO'}

\section{II.1.- Introducción}

El alfar romano de "El Rinconcillo" se sitúa en el término municipal de Algeciras (Cádiz), a ambos márgenes de la carretera local que comunica la Carretera Nacional 340 y la playa del mismo nombre. En la actualidad se encuentra a una distancia aproximada de unos 300 metros de la playa y a 500 metros del río de las Cañas o Palmones, aunque en época romana se ubicaba a la orilla del mar (Figura 1).

Este yacimiento arqueológico ha servido a menudo como referente en estudios que abordaban diversos aspectos de la economía romana del siglo I d.n.e., o bien, simplemente, en el establecimiento de analogías tipológicas de materiales anfóricos. No obstante, el desarrollo urbanístico descontrolado 
que ha caracterizado a la zona en la que se ubica ha impedido el establecimiento certero de su extensión y características. Hasta el momento se han realizado tres intervenciones arqueológicas en el alfar que se analizan someramente a continuación:

* Intervención 1: La primera intervención arqueológica realizada en el alfar de 'El Rinconcillo' se efectuó al detectarse la presencia de restos cerámicos que permitían suponer la existencia de un horno alfarero en las proximidades. La excavación se realizó entre el 22 de Agosto y el 1 de septiembre de 1966 bajo la dirección de D. Manuel Sotomayor (Sotomayor 1967), y durante la misma se documentaron dos hornos de ánforas en buen estado de conservación y numeroso material cerámico, parte del cual se encuentra depositado actualmente en salas municipales del Ayuntamiento de Algeciras. Posteriormente, estos hornos fueron declarados Monumento Histórico Nacional por Decreto de 16 de octubre de 1969.

Esta intervención proporcionó información referida fundamentalmente a las características tipológicas y datación tanto de los hornos, como del material cerámico que fue fabricado en ellos. Los hornos, que no fueron excavados en su totalidad, se encontraban unidos por un muro que los protegía por el lado oeste y parcialmente por el sur y norte. Eran de grandes proporciones, alcanzando los cuatro metros de diámetro, con una columna central de 0.56 metros de diámetro y treinta y dos arcos (de los cuales ocho eran principales y sostenían la mayor descarga de la estructura y otros veinticuatro secundarios a modo de refuerzos) construidos de ladrillo para soportar la parrilla hecha de adobe.

La mayoría de las ánforas recuperadas durante la excavación se fabricaron a mediados del siglo I d.n.e., y fueron destinadas al transporte de salazón y salsas de pescado. Las formas tipólogicas más representadas fueron las Dressel 7-13, conservándose además algún resto de ánfora de los tipos I (B-C) y 2-4 de la misma tabla tipológica.

* Intervención 2: La segunda actuación arqueológica se realizó en 1987 bajo la dirección D. Lorenzo Perdigones Moreno. El motivo de la misma fue la solicitud y concesión de licencia de obras para ejecutar un proyecto urbanístico residencial, que afectaba a una amplia extensión de terreno situado en el margen derecho de la carretera de acceso a la playa, en las proximidades de los hornos excavados veinte años atrás, donde se presumía la existencia de una parte del vertedero de la alfarería romana.

Se realizaron entonces 31 sondeos repartidos por el área que ocuparía el complejo residencial proyectado. Como resultado de esta actuación se delimitó una zona de interés arqueológico, en la que se detectó la existencia de una estructura arquitectónica cuya naturaleza no se determinó, ya que no se realizaron excavaciones arqueológicas en ese sector, cuya propiedad pasó a ser municipal, integrándose como zona verde de la urbanización y autorizándose la ejecución del proyecto presentado con las precauciones marcadas por la legislación vigente.

* Intervención 3: En 1991 durante el desarrollo de las obras previstas para la construcción del citado complejo residencial, se documentó la presencia de material cerámico -semejante al registrado durante la primera intervención- en el área en la que se había proyectado la construcción de una vía de acceso al mismo, por lo que se procedió a la paralización cautelar de las obras que se estaban realizando en dicho sector hasta que la realización de una excavación de urgencia determinara las características y naturaleza del hallazgo. Dicha excavación se llevó a cabo en su fase de campo durante los meses de octubre y noviembre de 1991.

La intervención arqueológica permitió documentar la existencia de un sector del complejo alfarero que había comenzado y finalizado su actividad productiva con anterioridad a la puesta en funcionamiento de los dos hornos excavados en 1966. Se trataba de un horno de reducidas proporciones, una pequeña 
superficie enlosada con piedras y ladrillos, y una esquina de una tercera estructura de naturaleza indeterminada que se extendía bajo la carretera actual, todo ello rodeado de un muro de 0.60 metros de grosor y entre 1 y 1.20 metros de altura conservada.

El interés del hallazgo radica particularmente en la sucesión de unidades estratigráficas que colmataron los citados restos arquitectónicos ya que, tras su abandono, el área en la que se ubica se utilizó como vertedero de los hornos colindantes. Ello permite establecer comparaciones relativas al volumen y características de la producción cerámica del alfar,'especialmente de las ánforas, dada su particular relevancia como indicativo económico en esta época.

\section{II.2.- Secuencia estratigráfica}

La secuencia estratigráfica del área excavada en la campaña de 1991 se sintetiza mediante la agrupación de las unidades estratigráficas más representativas en un total de cinco fases estratigráficas diferenciadas ${ }^{9}$ :

Fase I: Representa un periodo de tiempo indefinido previo al comienzo de las actividades productivas en la zona, resultando arqueológicamente estéril.

Fase II: Durante esta fase, datada en el segundo tercio del siglo I a.n.e., las instalaciones alfareras documentadas en el transcurso de la excavación se encuentran operativas. En primer lugar se construye un pequeño horno, una estructura cuya naturaleza no pudo determinarse construida con cascotes cerámicos y ladrillos y un muro que las protegía (Figura 2)

El horno se construyó con piedras irregulares y ladrillos, con una columna central compuesta de ocho hiladas de ladrillos cuadrangulares. Funcionalmente la estructura se podría dividir en una cámara de fuego de un metro de largo con una gran losa en el fondo sobre la que se había desplomado parte de una estructura de adobes, cuyos restos se localizaron profusamente aunque de forma dispersa, y un laboratorio de tendencia ligeramente oval, con la columna central y con siente bocas y cuellos de ánfora Dressel 1 encajadas entre el pilar y las paredes del horno a modo de radios que servían de soporte a la parrilla.

La segunda estructura se excavó parcialmente ya que se extendía bajo el acerado de la carretera de acceso a la playa, por lo que no quedó determinada su funcionalidad ni características completas. Poseía una altura de 0.30 metros, construida con hiladas de ladrillos y, en la superficie, cascotes de ánforas bien distribuidos.

Del muro de protección se excavó el lienzo oeste, que se interrumpía bruscamente cerca del acerado por la realización años atrás de una obra de infraestructura hidráulica, y el lienzo sur de forma parcial, ya que se extendía bajo unos locales comerciales en proceso de edificación. Se había construido con piedras, ladrillos y cascotes, con un acabado más regular hacia la zona interior.

Posteriormente, antes del abandono de este sector de la alfarería, se construyó un enlosado de tendencia cuadrangular de piedras y ladrillos de diverso tamaño y en el último momento de su actividad se situaron piezas cerámicas sobre una tegula sostenida probablemente, a juzgar por los clavos hallados y el color de la tierra circundante, por alguna pequeña estructura de madera.

9. Para una exposición detallada de la secuencia estratigráfica (Fernández 1995. En prensa) 
Fase III: Esta fase queda representada por una unidad estratigráfica sedimentaria que documenta el nivel de abandono de la actividad productiva en este área, sellando los restos de la fase anterior.

Fase IV: Documentada a través de varias unidades estratigráficas formadas por la acumulación de diverso material cerámico procedente del vertido de otros sectores de la alfarería entre finales del siglo I a.n.e. y el primer cuarto del siglo I d.n.e..

Fase V: Segunda fase de vertidos de materiales cerámicos en la zona hacia el segundo cuarto del siglo I d.n.e., cubriendo la práctica totalidad del área excavada.

\section{II.3.- Evolución de la producción cerámica}

\section{II.3.a.- Introducción}

Los materiales arqueológicos documentados durante la excavación fueron clasificados e individualizados en base a su pertenencia a las distintas unidades estratigráficas registradas durante la excavación.

Para poder comparar el volumen de materiales de distinto tipo a través de las diferentes fases cronológicas se procedió a cuantificar los fragmentos cerámicos pertenecientes a bordes de tipología bien definidas a través de dos procedimientos distintos que teóricamente permitirían contrastar la información obtenida:

— La cuantificación simple de los fragmentos: Permitió establecer una aproximación a la variabilidad cuantitativa de los distintos tipos y formas cerámicas para poder comparar su volumen dentro de cada unidad estratigráfica y realizar gráficos sencillos acerca su evolución en las distintas fases.

- Cálculo del porcentaje de circunferencia de los bordes conservados: Para solventar el problema de la fragilidad de determinados materiales, como los vasos de paredes finas, en relación con otros mucho más compactos y más difícilmente rompibles, como ánforas o morteros, que podrían distorsionar los resultados obtenidos en base a la simple cuantificación de los fragmentos cerámicos, se realizó el cálculo del porcentaje de circunferencia que describían los bordes de una misma forma cerámica (Arthur-Ricci 1983). Este método trata de realizar una aproximación al número de posibles objetos completos conservados estableciendo un máximo y un mínimo. No obstante, para su óptima utilización, se requiere que las formas cerámicas estén muy exactamente definidas, y que los fragmentos individualizados dentro de una determinada forma posean exactamente las mismas características formales. Por ello se procedió a la precisa individualización de formas cerámicas teniendo como base sus características morfológicas, observando que en el conjunto del alfar se documentaban un total de 166 formas distintas, muchas de las cuales sólo se diferenciaban entre sí por el tipo de cocción o por la variación en el grosor de sus paredes. Los resultados obtenidos no fueron en absoluto representativos ya que la mayoría de dichas formas estaban representadas por un solo fragmento, o por varios de ellos cuya suma de porcentajes de circunferencia no llegaba a cubrir 360 grados con lo cual la fluctuación resultante se situaba en este último caso en un mínimo de un objeto completo y en un máximo de, por ejemplo, cinco (tantos como fragmentos).

Por todo ello, la cuantificación simple de los fragmentos documentados ha servido de única base a la hora de reflejar el proceso evolutivo de la producción del alfar, por cuanto el problema de la elevada predisposición a la fractura de los objetos de paredes finas no distorsiona en este caso de forma muy destacada los resultados, ya que la mayor parte de los fragmentos cerámicos conservados pertenecen 
a ánforas y cuando en el interior de alguna unidad estratigráfica los de paredes finas superan en volumen a estos últimos es porque su número resulta prácticamente insignificante.

Por último se realizaron análisis sobre la composición química y mineralógica de las pastas cerámicas en el Departamento de Cristalográfica, Mineralogía y Química Agrícola de la Facultad de Química de la Universidad de Sevilla, de cuyos resultados se incluye un resumen en este trabajo.

\section{II.3.b.- Cuantificación del material cerámico}

El estudio de los materiales cerámicos documentados en el 'El Rinconcillo' presenta una importante y definida evolución tipológica desde el segundo tercio del siglo I a.n.e. a mediados del siglo I d.n.e., evolución que permite caracterizar las tendencias de la producción de sus presuntos contenidos, y con ello, una aproximación a la estructura productiva de la comarca en dicho marco cronológico.

La secuencia estratigráfica presentada anteriormente muestra la existencia de una serie de unidades estratigráficas agrupadas por fases cronológicas definidas, cuyos materiales cerámicos característicos se analizan a continuación:

* Fase II (Lámina 1 y Lámina 2, 1-8): Representa la primera fase productiva del alfar localizada en el área excavada en la campaña de 1991. Analizando los gráficos descriptivos realizados en base al número de fragmentos de borde registrados en dicha fase (Figura 3) se puede concluir que entre las formas cerámicas que se han documentado, y que se han agrupado atendiendo fundamentalmente a su funcionalidad, destaca la primacía de los fragmentos de tapaderas que en más de un $80 \%$ pertenecen al tipo que se ha denominado 1, empleadas en el sellado de las ánforas y caracterizas por poseer un diámetro medio de $11 \mathrm{cms}$, oscilando siempre entre los 10 y los $15 \mathrm{cms} .{ }^{10}$ (Lámina 1,4). A continuación son los pequeños vasos de paredes finas los más numerosos (Lámina 2, 3-5), seguidos de las fuentes (Lámina 1, 7), cazuelas (Lámina 1, 10-12) y cubiletes (Lámina 1, 18 y Lámina 2, 1-2).

Las ánforas sólo aparecen en mayor número que ollas (Lámina 1, 17), morteros y otros materiales menos significativos en número, y pertenecen exclusivamente a los tipos Dressel 1A (Lámina 1, 1-2 y 9) y Dressel 1 B-C (Lámina 1, 5-6), siendo más numeroso el primer tipo. A pesar de ello el número de fragmentos de ánforas en términos absolutos no es muy significativo (sólo se han contabilizado 8 fragmentos de bordes).

En esta fase destaca la presencia de un fragmento de cerámica campaniense B de la forma 6 de Lamboglia (1979) (Lámina 1, 15) que, junto con el resto de materiales asociados, establece un arco cronológico situado en el siglo I a.n.e., antes de la época de Augusto.

* Fase III (Láminas 2, 9-16; Láminas 3, 4 y 5 y Lámina 6, 1-18): Representa el periodo de abandono del área anteriormente citada. Los gráficos (Figura 3) continúan mostrando la preponderancia del número de tapaderas, que en un $34 \%$ siguen siendo del tipo 1. Las ánforas se sitúan en el segundo lugar en cuanto a volumen de fragmentos (30\%), siendo los porcentajes del resto de los tipos cerámicos prácticamente insignificantes. Podría destacarse, no obstante, por su valor para el establecimiento de

10. Las tapaderas del tipo 2 poseen forma aplanada y sin reborde oscilando entre los 20 y los $25 \mathrm{cms}$. de diámetro (Lámina $6,15)$, mientras que las tapaderas del tipo 3 se caracterizan por su forma acampanada y reborde, con un diámetro superior a los 25 centímetros de diámetro (Lámina 6, 14). 
una cronología más o menos precisa, un fragmento de lucerna delfinoide (Lámina 6, 16) del tipo Dressel 2 típica del siglo I a.n.e., fechada entre los años 50 y 20 en el estrato VI A de Albintimilium (Lamboglia 1979), entre el segundo y tercer cuarto del siglo I a.n.e. en el campamento militar romano de Lomba do Canho (Castro-Guerra-Fabiâo 1991) y a mediados del siglo I a.n.e. en el Foro de Cesar y en los pecios Dramont A y Planier 3 (Ricci 1973).

Se registra un sólo fragmento de ánfora Dressel 1A (Lámina 5, 1), siendo las Dressel 1 B-C las dominantes con un $88 \%$ de los fragmentos cuantificados (Lámina 2, 9-16; Lámina 3; Lámina 4, 1-2 y 6-7 y Lámina 5, 7). Por otra parte, aparecen algunos otros (10\%) pertenecientes a ánforas que podrían emparentarse tipológicamente con las Dressel 21-22 "' (Lámina 4, 3-5). Este tipo de ánforas se había documentado ya en Bolonia (Domergue 1969; 1973) y en el Cerro del Mar (Arteaga 1985), habiendo sido fechado entre los años 50 y 30 a.n.e. en Albintimilium (Lamboglia 1955), y entre el segundo y tercer cuarto del siglo I a.n.e. en el campamento de Lomba do Canho (Guerra-Fabiâo 1988; 1989).

Puede destacarse, por último, la existencia de fragmentos de vasos de paredes finas y cazuelas denominadas 'cuencos de borde plano', por M. Vegas pertenecientes al tipo 4 de su tabla tipológica (Lámina 5, 9) datadas en época republicana (Vegas 1973), así como las tapaderas que las cubrían que se han incluido en el tipo 3 (Lámina 6, 14). Cazuelas y tapaderas de las mismas características tipológicas fueron halladas en el la Villa Nueva de Algeciras en 1967, formando parte de una necrópolis de incineración mediante su utilización como urnas cinerarias. Dicha necrópolis fue datada entre finales de la época augustea y la época claudia (Rodríguez Oliva 1977), aunque la propia tipología de estas urnas y el ajuar (consistente en diversos tipos de ungüentarios de vidrio), quizá permitiría atrasar dicha cronología, ya que, al menos en el alfar de "El Rinconcillo", no se fabrican los citados cuencos con posterioridad al cambio de era.

* Fase IV (Lámina 6, 19-20; Lámina 7 y Lámina 8, 1-13): En esta fase se documenta por primera vez una mayor cantidad de fragmentos de ánforas que de cualquier otra forma cerámica (Figura 4). Dichas ánforas siguen siendo en su mayoría de la forma Dressel 1B-C (49\%) (Lámina 7, 1-5), aunque es significativo el porcentaje de ánforas Dressel 7-13 (37\%) (Lámina 7, 6-11) que hasta este momento no se habían registrado (Lámina 7, 6-11). En tercer lugar se sitúan las Dressel 21-22 (14\%) (Lámina 7, 14-15).

Las tapaderas se continúan produciendo, aunque ha disminuido su volumen, suponiendo las del tipo 1 un $44 \%$ del total. Entre el resto de las formas cerámicas destacan las cazuelas (9\%) fluctuando los demás tipos en unos porcentajes casi insignificantes.

* Fase V (Lámina 8, 14-17; Láminas 9 y 10): Las ánforas siguen ocupando el primer lugar en cuanto a volumen de fragmentos de borde registrados (Figura 4), aunque ahora las Dressel 7-13 (54\%) (Lámina 9, 1-5, 8-9 y 15-16) rebasan claramente a las Dressel 1 B-C (31\%) (Lámina 9, 6-7), que, además, sufren una transformación tipológica, ya que mientras en las anteriores fases el diámetro de la boca de este último tipo oscilaba entre los 15 y $16 \mathrm{cms}$. ahora la mayoría posee un diámetro de boca entre los 18 y $20 \mathrm{cms}$. Por último también se documentan algunos fragmentos de ánforas afines al tipo 21-22 de Dressel (14\%) (Lámina 8, 14-17 y Lámina 9, 10-13).

11. Este tipo, no obstante, ha sido individualizado al margen de esta clasificación por C. Fabiâo a partir de los hallazgos anfóricos registrados en el yacimiento de Lomba do Canho (Fabiâo 1989). 
Tras las ánforas siguen siendo las tapaderas las más representadas (11\%), volviendo a destacar claramente las del tipo 1 (88\%). El resto de los tipos cerámicos presentan mucha variedad, tal y como ocurría en las fases anteriores, pero representan valores muy bajos en el conjunto de la muestra.

\section{II.3.c.- Caracterización mineralógica de las pastas cerámicas}

En el estado actual de la investigación anfórica resulta imprescindible superar el mero estudio morfológico de los envases y tender hacia la caracterización química y mineralógica de las pastas cerámicas, con la finalidad de discriminar producciones y, con ello, determinar rutas comerciales establecidas entre los centros productores y los lugares de destino ya que, con frecuencia, la imitación de tipos anfóricos en lugares distanciados puede inducir a error en el establecimiento de dichas rutas y en la evaluación del volumen de exportaciones o importaciones de una determinada procedencia, teniendo en cuenta, sobre todo, el extraordinario valor que poseen las ánforas como indicador económico de la antigüedad. La efectividad de este tipo de análisis está ya demostrada en multitud de investigaciones recientes (Vendrell-Molera-García 1992; Vendrell-Pradell 1992; Fabri-Casadio-Pedeli 1989; HuertasHuertas 1991; etc.) en las que se han aportado datos de interés sobre la evolución de la tecnología de los hornos, las fuentes de adquisición de las arcillas, el establecimiento de etapas de fabricación, etc., aunque, como se ha apuntado con anterioridad, sólo se incluye en este trabajo un resumen de los resultados de los análisis realizados a las muestras cerámicas de 'El Rinconcillo' ${ }^{12}$.

En la Tabla 2 se muestran las agrupaciones de muestras obtenidas tras la realización de distintas analíticas (difracción de rayos $\mathrm{X}$, imágenes de luz reflejada de secciones pulidas y porosimetría de mercurio) bajo la dirección de D. Ángel Polvorinos del Río (Departamento de Cristalografía, Mineralogía y Química Agrícola de la Universidad de Sevilla). En las tres primeras columnas se especifica la información referida al número de muestra, fase, número de inventario y tipología del objeto al que perteneció. Las cuatro siguientes recogen datos referidos a la temperatura de cocción a las que fueron sometidas y los grupos mineralógicos, morfométricos y porosimétricos en los que han quedado integradas.

En base a las temperaturas de cocción a las que fueron sometidas las cerámicas, se observa la conformación de tres grupos de muestras. En los dos primeros (TeI y TeII) parece existir una correlación directa entre el la posición estratigráfica de los objetos y las temperaturas a las que fueron cocidos: a más antigüedad temperaturas más altas. Sin embargo esta tendencia no se ajusta al tercer grupo de muestras en las que han quedado incluidos objetos pertenecientes a unidades estratigráficas de distinta cronología. Por otra parte parece más evidente la correlación entre las temperaturas de cocción y las tipologías cerámicas. Las ánforas vinarias Dressel 1A y los vasos de paredes finas fueron sometidos a las más altas temperaturas de cocción, las ánforas de salazones Dressel 7-11 y un tipo de cerámica de imitación campaniense a temperaturas intermedias, mientras que las ánforas de salazones Dressel 21-22, la tradicionalmente considerada ánfora vinaria Dressel 1C y sus tapaderas y la cerámica gris pseudocampaniense a las más bajas temperaturas.

Por otra parte, los análisis mineralógicos establecen las primeras matizaciones a esta primera agrupación. Según la mineralogía de las muestras estudiadas se establecen un total de cuatro agrupaciones de fragmentos.

12. Para un análisis detallado de los resultados obtenidos (Gómez-Fernández Polvorinos 1995). 
Al igual que en el caso anterior, parece descartarse la existencia de una variabilidad mineralógica en relación directa con la evolución productiva del alfar, siendo de nuevo la tipología del objeto y/o su funcionalidad la que marca sus características mineralógicas.

TABLA 2

\begin{tabular}{|c|c|l|c|c|c|}
\hline Muestra & Fase & \multicolumn{1}{|c|}{ Tipología } & Mineralogía & Morfometría & Porosimetría \\
\hline M1 & Fase IV & Dressel 7-11 & Mi II & Mo II & Po I \\
\hline M2 & Fase V & Dressel 7-11 & Mi P & Mo P & Po P \\
\hline M3 & Fase IV & Dressel 21-22 & Mi I & Mo I & Po I \\
\hline M4 & Fase II & Dressel 1A & Mi III & Mo II & Po II \\
\hline M5 & Fase II & Dressel 1A & Mi III & Mo P & Po II \\
\hline M6 & Fase IV & Dressel 7-11 & Mi II & Mo II & Po II \\
\hline M7 & Fase V & Dressel 7-11 & Mi II & Mo II & Po II \\
\hline M8 & Fase II & Pseudocamp. & Mi I & - & Po III \\
\hline M9 & Fase II & Vaso pd. finas & Mi III & - & - \\
\hline M10 & Fase II & Camp. imitac. & Mi II & Mo P & Po III \\
\hline M11 & Fase II & Dressel 1A & Mi III & - & Po II \\
\hline M12 & Fase III & Tapadera ánf. & Mi I & - & Po I \\
\hline M13 & Fase III & Dressel 1C & Mi I & Mo I & Po I \\
\hline
\end{tabular}

En relación con la morfometría se han establecido dos grupos de muestras y varios casos peculiares, no pudiéndose realizar los análisis en las muestras M8, M9, M11 y M12 por la imposibilidad de manipularlas adecuadamente debido a su escasa compacidad:

Lo más destacable de estas agrupaciones es la establecida de nuevo entre las muestras M3 y M13 (Dressel 21-22 y Dressel 1C respectivamente), así como la de las ánforas de salazones Dressel 7-11 (M1, M6 y M7) a las que se les asocia en este caso una muestra perteneciente a un ánfora vinaria Dressel 1A.

Por último, se han definido cuatro agrupaciones de muestras en base a su porosimetría. El análisis de porosimetría de mercurio discrimina, tal y como aparece en la tabla, funcionalmente los objetos: por un lado las ánforas Dressel 1A, por otro las cerámicas de lujo y, en tercer lugar de nuevo la asociación del ánfora de salazón Dressel 21-22 con la Dressel 1C y un ejemplar de Dressel 7-11, mientras que las otras dos muestras de este último tipo presentan características mixtas entre el primer grupo y el segundo.

De todo ello se desprende que el empleo de diferentes técnicas de elaboración y composición de las cerámicas estudiadas se basaron más en la distinta funcionalidad para las que fueron producidas que en la existencia de una clara evolución temporal. De este modo, en el conjunto de la producción anfórica, las Dressel 1A se caracterizaron por las altas temperaturas a las que fueron sometidas en el proceso de cocción que dieron lugar a la aparición de fases cristalinas que las discrimina desde el punto 
de vista mineralógico, aunque su composición inicial fuera semejante a las del resto. Por otra parte presentan un bajo volumen de poros acumulado, hecho que puede estar en función de las características del producto transportado. Las ánforas de salazón del tipo Dressel 7-11. se distinguen mayoritariamente por haber sido cocidas a temperaturas intermedias y por poseer como las anteriores un volumen de poros acumulado bajo aunque se distinguen dos sistemas de poros conectados, hecho que se evidenciará más claramente en las ánforas de tipo Dressel 21-22 y Dressel 1C. En efecto, además de por su cocción a bajas temperaturas, estos dos tipos anfóricos se distinguen por la clara separación de ambos sistemas de poros, poseyendo, además, un volumen total de poros acumulado mayor, lo que las haría más permeables ${ }^{13}$. Este hecho sugiere la posibilidad de que las ánforas del tipo Dressel 1C que se fabricaron en 'El Rinconcillo' no se empleasen para transportar vinos sino productos derivados del pescado tal y como parece probado para las Dressel 21-22, con las que se asocia permanentemente en todos los análisis efectuados.

En el conjunto de las muestras de ánforas que se han estudiado el caso más peculiar queda representado por la muestra M2, perteneciente a un ánfora del tipo Dressel 7-13, que sin lugar a dudas es un objeto de procedencia foránea.

El resto de las cerámicas analizadas evidencian la existencia de un proceso de selección de materiales de mejor calidad y de un cuidado proceso de cocción en la fabricación de cerámicas de lujo de imitación campaniense. Por otra parte, los vasos de paredes finas, si bien no se elaboraron a partir de unos materiales especialmente selectos, fueron sometidos a las más altas temperaturas para proporcionarles la compacidad y dureza que requerían.

\section{II.3.d.- Interpretación}

Tal y como se ha expuesto anteriormente, en el sector 3 se registra una fase estratigráfica previa a la ocupación de la zona, una segunda de construcción y uso de las instalaciones excavadas en la misma y otras tres de colmatación diferenciadas, cuyo estudio ha permitido analizar la evolución de la producción anfórica del alfar romano de 'El Rinconcillo'.

Durante la segunda fase estratigráfica se construyen las estructuras más antiguas conocidas hasta el momento en el alfar y se ponen en explotación. Del estudio de los materiales cerámicos de esta fase y la posterior de abandono, que forman un conjunto bastante homogéneo, se desprende la existencia de tres tipos de ánforas (Dressel 1A, Dressel 1B-C y Dressel 21-22), siendo los fragmentos de ánforas Dressel 1B-C ampliamente dominantes con un $78 \%$ del total.

La imitación de las ánforas Dressel 1C, es situada por M. Beltrán (1977) en época augustea. No obstante, en 'El Rinconcillo' estas ánforas aparecen asociadas en la segunda fase estratigráfica a varios fragmentos de boca de ánforas Dressel $1 \mathrm{~A}$ y a vasos de paredes finas correspondientes al tipo 26-1 de Vegas (Vegas 1973) datado en Pollentia en época tardorrepublicana. Además, la asociación de ambos tipos anfóricos con fragmentos de cerámica campaniense B y la total ausencia de fragmentos de otras ánforas imperiales, lleva a retrasar la cronología al menos hasta el segundo tercio del siglo I a.n.e.

El horno que se documenta en este periodo ofrece asimismo características originales. Las medidas del laboratorio condicionan y limitan la tipología de los objetos cocidos en el mismo, y su forma sirve

13. En efecto estudios recientes (Thierrin-Michael 1995) muestran que las ánforas vinarias (tanto Dressel 1 como Dressel 2-4) fabricadas en Italia alcanzaron temperaturas de cocción que rondaban los $950^{\circ} \mathrm{C}$, mientras que las Dressel $1 \mathrm{C}$, al igual que las Dressell 21-22 y las tapaderas de ánfora, de 'El Rinconcillo' no soportaron durante la cocción una temperatura superior a $\operatorname{los} 650^{\circ}$. 
de precedente a los hornos de columna central con arcos radiales, con la curiosa particularidad de que sus reducidas dimensiones permitieron la reutilización de las bocas y cuellos de ánforas Dressel 1B-C como radios que en número de ocho fueron encajados entre las paredes del horno y el pilar central de ladrillos cuadrangulares, sobre los que se sustentaría la parrilla y la pequeña cúpula de adobe que, aunque no se ha conservado, sí ha dejado numerosos restos.

Se ha de incidir del mismo modo en el gran volumen de pequeñas tapaderas que se documentan en este momento, y que constituyen el tipo cerámico más representado, seguido de los vasos de paredes finas. Ambas formas podrían haber sido susceptibles de cochura en un horno de reducidas dimensiones, aunque la aparición de numerosas tapaderas tanto en los alrededores como en el interior del horno permiten sugerir la hipótesis de que se cocían en él principalmente este tipo de objetos.

Por otro lado, es de destacar el bajísimo porcentaje de ánforas destinadas al transporte de salazón que se reduciría al $8 \%$ si se acepta el posible contenido piscícola de las ánforas Dressel 21-22, lo que podría hacer suponer que hasta finales del s. I a.n.e. el producto mayoritariamente exportado desde esta zona de la bética fue el vino, siendo a partir del cambio de era cuando la comercialización del salazón y las salsa de pescado ocupan un lugar preferente, diversificándose la tipología de ánforas fabricadas mediante la incorporación de las Dressel 7-13, dedicadas exclusivamente a contener estos nuevos productos.

No obstante, parece poco probable que a mediados del siglo I a.n.e., cuando la exportación de vinos italianos y el proteccionismo estatal sobre este producto aún son efectivos ${ }^{14}$, una zona como la de la Bahía de Algeciras, tradicionalmente pesquera y ganadera, estuviera en condiciones de producir vinos tanto para su propio abastecimiento como para la exportación, al menos en las condiciones comerciales existentes en el siglo I a.n.e.. Si, por otra parte, en el anverso de algunas monedas conservadas de Iulia Transducta, identificada a menudo como la Algeciras romana, aparece un racimo de uvas, este no es un dato determinante para demostrar la existencia o inexistencia del producto ${ }^{15}$ (Marín-Prieto 1987), demostración que sólo podrá realizarse con un adecuado estudio paleoambiental del territorio, y, aún menos, de su transformación y exportación ${ }^{16}$.

Una segunda opción sería la posibilidad de que se produjeran unos envases cerámicos destinados a contener una producción vitícola exterior. No obstante la zona de la Bahía de Algeciras ofrece muchas

14. "Il protezionismo monopolistico, reso possibile anche dalla fluidità antiburocratica di un imperialismo variegato, non ancora cristallizzatosi in stato imperiale, mirava a impedire un allargamento dell'offerta, che avrebbe fatto crolare la sovraestimazione del vino e delle terre italici, grazie alla concorrenza (...). Con la pax romana crollano le barriere che chiudevano il mercato all'offerta diversificata delle rampanti province occidentali. Il primo e medio impero vedranno un mercato sempre meno monopolistico e sempre più concorrenziale (...). I due secoli seguenti saranno quelli del grandissimo commercio transmarino dei vini, ma l'attore non sarà più unico e sull'ampia scena imperiale reciterà ormai un'intera compagnia. D'ora in poi l'Italia non basterà più né alle province né a sé stessa, come fin'ora era accaduto." (Carandini 1989. Pgs.: 511-512)

“Il est vraisemblable qu'à l'époque de César pas une goutte de vin n'y arrivait del provinces occidentales; les choses ont bien changé au milieu du règne d'Auguste" (Tchernia 1987. Pg.: 53).

15. No obstante este recurso es muy utilizado en los estudios que se han realizado sobre economía antigua en general y de la zona del Estrecho de Gibraltar en particular (Ripoll 1988), aunque quizá su valor debería ser relativizado e incorporado al resto de la información recogida de otras fuentes y no establecido como dato determinante por sí solo.

16. De hecho, ya en el siglo XIX con una tecnología más avanzada y un mercado más regulado que el existente en época romana, si bien se cultivaban pequeños viñedos en la zona, la mala calidad del suelo y el clima que lo caracteriza no permitía su cultivo a gran escala, la mayor parte de la producción de uva se consumía en verdeo y el vino no alcanzaba a abastecer a la población teniendo que ser importado. Madoz señala (Madoz 1990) como mientras entre 1843 y 1844 salen desde el puerto de Algeciras barcos que entre otras mercancías incluyen un total de 360 arrobas de vino, en los mismos años entran en puerto un total de 38.445 . 
dificultades de comunicación terrestre con el interior, por lo que la salida de este producto se produciría más bien desde las costas malagueñas o, por el oeste, desde la costa o a través de ríos y esteros navegables (Chic 1984) ${ }^{17}$.

Mención aparte merece el alfar de Guadarranque localizado por M. Beltrán en las proximidades de Carteia (Beltrán 1977). Según se desprende de los materiales documentados en superficie se fabricaron fundamentalmente ánforas vinarias del tipo Dressel 2-4, aunque se atestigua, en menor medida, la existencia de fragmentos anfóricos pertenecientes a otros tipos. La producción de estos envases destinados al comercio del vino permitiría sugerir que la fuente de riqueza de Carteia no fue sólo la derivada de las actividades industriales relacionadas con la elaboración de productos piscícolas, sino que procedería también del cultivo de vides y exportación de vinos. Ante esta posibilidad cabría, no obstante, hacer ciertas puntualizaciones:

1: El terreno apto para el cultivo en El Campo de Gibraltar es muy escaso. No obstante, aunque este terreno fuera empleado mayoritariamente en el cultivo de vides que, por otra parte, puede cultivarse en circunstancias menos propicias que los cereales (aunque redundando en la calidad del producto), la producción vitícola obtenida no debió adquirir un volumen muy apreciable.

2: Aún asumiendo la posibilidad de que se produjera un excedente susceptible de ser exportado, ello no ocurriría hasta el siglo I d.n.e. El tipo de ánfora Dressel 2-4 sustituye a las Dressel 1 en Italia en época de Augusto, y las imitaciones hispánicas datan de los primeros decenios del siglo I.

En Baelo Claudia (Tarifa, Cádiz), se constató la existencia de factorías de salazón de pescado ya a fines del siglo II a.n.e., con lo cual se confirmaba la dependencia económica de la población de las actividades relacionadas con la pesca y la elaboración de conservas y salsas de pescado desde un primer momento, ya que son los restos más antiguos documentados en el yacimiento, que coinciden cronológicamente con las primeras series monetales de Baelo, fechadas entre el 133 y el 105 a.n.e. (Domergue 1973). En los niveles inferiores pertenecientes a dicha factoría aparecen ánforas de los tipos Dressel 1A, Dressel 1B-C, cerámica campaniense y de paredes finas republicanas. Sólo a finales del siglo I a.n.e. comenzarían a producirse las ánforas de salazón de los tipos 7-13, después del abandono de este sector antiguo de la factoría. También antes del cambio de era, se empiezan a registrar los primeros fragmentos pertenecientes a ánforas emparentadas con las Dressel 21-22, destinada al transporte de productos derivados del pescado. La inexistencia de contenedores específicos de salazón en la época de producción de la factoría, y la fecha temprana de la misma, hacen sugerir a C. Domergue la posibilidad de que en las ánforas tradicionalmente vinarias se transportase desde Baelo salazón de pescado (Domergue 1973: 115).

En los hornos de Torre Alta (San Fernando, Cádiz), se ha documentado recientemente la presencia de restos de ánforas que tipológicamente se han asociado a la exportación de vinos de la Campania en el siglo II a.n.e.. Sin embargo, su aparición en el alfar junto a ánforas púnicas destinadas al transporte de salazón de pescado y la existencia de un sello en un fragmento de panza representando una figura humana portando un pez de gran tamaño, posiblemente un atún, sugiere una imitación de la forma de origen itálico para contener estos salazones (Frutos-Muñoz 1994).

17. Las dificultades en las comunicaciones terrestres de la Bahía de Algeciras ha sido puesta de manifiesto a menudo por los viajeros que desde el siglo XVI dejaron constancia escrita de su paso por la comarca (Bueno 1988). El mismo Madoz en su Diccionario Geográfico-Estadístico-Histórico de España afirmaba que "difícilmente habrá en España un punto más descuidado en los medios de comunicación" (Madoz 1990) 
Del mismo modo, en todas factorías de salazón de época púnica excavadas en Cádiz, se documentan, junto a las ánforas de salazón púnicas locales, ánforas grecoitálicas semejantes a la anterior que son consideradas como importaciones (Muñoz-Frutos-Berriatua 1988). La determinación exacta de su origen foráneo o bien local, mediante la imitación del modelo original, podría aportar una información valiosa al respecto.

En las excavaciones realizadas en el Cerro del Mar (Málaga) en el año 1982, se documentó una completa secuencia estratigráfica que permitió estudiar diferentes complejos anfóricos desde finales del siglo II a.n.e a principios del siglo II d.n.e. (Arteaga 1985). El complejo más antiguo lo componen ánforas de tipología "púnica occidental", y están relacionadas con la producción de salazón de pescado. Esta industria también quedó documentada por la presencia de restos de salazón y de una pileta que, por sus características, parece relacionarse con este tipo de industria. En el complejo inmediatamente posterior se asocia este tipo de ánforas a variantes de las Dressel 1B-C, que sufrirán una evolución tipológica hasta comienzos del siglo I d.n.e., conviviendo con ánforas de salazones de época romana como las Dressel 7-13 o las Dressel 21-22.

El estudio de las pastas con las que se elaboraron estas ánforas, permitiría comprobar si se trataban de importaciones de la península itálica o son imitaciones locales y contrastar la secuencia estratigráfica de Baelo Claudia (con la salvedad de que esta es una fundación romana en la que no se documentan ánforas púnicas), el Cerro del Mar y el Rinconcillo, en las cuales el común denominador sería la asociación de ánforas vinarias Dressel 1B-C con sitios donde se constata desde fecha temprana la instalación de factorías para la elaboración de productos derivados del pescado.

Estos hallazgos, si bien no son determinantes en ningún caso, permiten proponer la posibilidad de que las ánforas vinarias Dressel 1B-C fabricadas en El Rinconcillo, sirvieran para contener productos derivados del pescado que se producían en las factorías de salazón cercanas. De hecho han aparecido en el mediterráneo y las costas portuguesas algunas ánforas de este tipo con contenido frutícola y piscícola (Fabiâo 1987), lo que ha flexibilizado la relación que de forma absoluta se había establecido entre las ánforas Dressel 1B-C y el vino itálico.

En esta línea se inscriben los resultados de las excavaciones arqueológicas realizadas en el puerto romano de Cosa. Dichos resultados han permitido afirmar a sus excavadores el posible origen hispano de la forma Dressel 1C como precedente de la Dressel 12, señalando la zona de Cádiz y de Algeciras como posibles centros de producción de este tipo anfórico destinado al transporte de salazón de pescado y 'garum' (Will 1979; 1987), tesis compartida por F. Laubenheimer tras su estudio de las ánforas de Ruscino (Laubenheimer 1980).

A partir de la época de Augusto, la integración económico-administrativa de los territorios de ultramar en un marco de referencia superior, el del Estado Imperial, provoca que los poderes económicos de las provincias compitan por el control de determinadas actividades mercantiles (Carandini 1980). Una de las consecuencias de esta competencia, establecida en términos económicos, sería la fabricación de contenedores diferenciados que identificasen los productos que contenían, así como su procedencia (Almagro 1983).

No obstante, en la etapa inmediatamente anterior, en la comarca del Campo de Gibraltar, pudo producirse una imitación de las ánforas itálicas más extendidas por el Mediterráneo en esos momentos para contener los productos derivados del pescado que se fabricaban en la zona y que resultarían fácilmente exportables. Posteriormente, con la introducción en la producción de las ánforas Dressel 7-13, características de la Bética, no dejarían de producirse las anteriores, aunque ya de forma más limitada y modificando su tipología hacia formas que presentan un diámetro de boca más amplio, pasando de los $15 \mathrm{cms}$. de media 
en los primeros momentos, a los $18 \mathrm{cms}$. en las ánforas datadas en el segundo cuarto del siglo I d.n.e, modificación que facilitaría la manipulación de las mismas en razón del producto posiblemente exportado.

Esta hipótesis, no obstante, podría ser matizada ya que no existen actualmente datos lo suficientemente consistentes como para afirmar su validez. De hecho, si se confirmara la extensión del cultivo de la vid en aquellas zonas óptimas para el cultivo, se podría aceptar la posibilidad de que las ánforas Dressel 1B-C contuvieran un vino que, aunque de baja calidad, fuera competitivo por su bajo precio en el mercado (Sáez 1987) -a pesar de la prohibición de competir con los vinos itálicos-, e incluso con ambos productos a la vez, vino y salazón. Un adecuado estudio paleoambiental del territorio aclararía definitivamente este extremo.

\section{CONCLUSIONES}

\section{La salazón de pescado y el desarrollo económico del Campo de Gibraltar}

La mayor riqueza explotable y capitalizable de la comarca del Campo de Gibraltar ha sido históricamente la derivada de los recursos pesqueros de sus aguas. Estos recursos fueron sin duda aprovechados desde el comienzo de la presencia humana en la zona tal y como se deduce de recientes estudios que se han realizado en relación con la presencia de ictiofauna en yacimientos costeros ibéricos (RosellóMorales 1988; Morales-Roselló 1988). Según se desprende de los resultados de dichos estudios, en el litoral andaluz occidental se evidencia la explotación de este recurso desde, al menos, el Neolítico. Pero, lo que es más importante, en esta franja litoral se constata la existencia de un tipo de pesca pelágica, que requeriría de unas artes pesqueras mucho más evolucionadas que las desarrolladas para la pesca litoral, desde esta temprana cronología.

Posteriormente, durante la colonización fenicia en estas costas, el volumen de restos de ictiofaunas en los yacimientos arqueológicos de la costa aumenta considerablemente, diversificándose asimismo las especies pelágicas capturadas (carángidos, túnidos, escómbridos y escualos). No obstante, estas evidencias, por el momento, no permiten afirmar más que la explotación de un recurso natural para el autoconsumo o el intercambio a escala reducida y, en el Campo de Gibraltar, ni siquiera existen evidencias arqueológicas que demuestren la existencia de una explotación intensiva de los recursos marinos en época protohistórica.

No sería hasta el siglo I a.n.e. cuando la riqueza pesquera del Estrecho empezó a explotarse intensivamente, con vistas a la comercialización de unos productos ampliamente aceptados y demandados en el mercado mediterráneo. La proliferación de factorías de salazón, almadrabas o alfares productores de los envases para las conservas son muestra de ello. Es a partir de ese momento cuando se constata en el Campo de Gibraltar un aumento espectacular de la ocupación del territorio, cuya intensidad y extensión no sería otra vez alcanzada hasta época moderna, no sólo en base a pequeños núcleos de carácter rural y disperso, sino también en poblaciones que como Barbésula, Carteia o Baelo Claudia, adquirieron extraordinaria relevancia y que, sin lugar a dudas, tuvieron en la pesca e industrias derivadas, su base económica fundamental.

De hecho, si bien es cierto que la mayoría de los asentamientos, tanto en época protohistórica como romana, se ubican mayoritariamente en terrenos de gran capacidad agrícola potencial, se debe de tener muy en cuenta que en el conjunto del Campo de Gibraltar este tipo de suelos supone tan sólo el $9 \%$ del total, por lo que sólo podría generar una producción volcada fundamentalmente hacia el autoabastecimiento de la población. Por otra parte, la ganadería, que debido a las características del territorio, pudo 
convertirse en una actividad económica extendida, muy raramente llega a capitalizarse, puesto que estaría, excepto en los casos de cría de ganado para el consumo familiar, en manos de las aristocracias locales como medio de adquirir prestigio, de forma que no parece probable que pudiera constituir un revulsivo económico importante. De esta forma, y según parece desprenderse de los datos que se han analizado, las industrias derivadas de la pesca se configuran en el Campo de Gibraltar, como principal motor de desarrollo económico de la zona.

Este desarrollo parece adquirir su punto álgido entre la segunda mitad del siglo I a.n.e. y mediados del siglo I d.n.e.. Confirman esta aseveración las excavaciones arqueológicas realizadas en Carteia, Baelo Claudia y 'El Rinconcillo'. En las excavaciones realizadas en Carteia (Presedo 1982; Presedo-Caballos 1987a; 1987b; 1988), se ha documentado una etapa de auge constructivo en este periodo, fundamentalmente en época tardorrepublicana y augustea, posiblemente detenido durante el desarrollo de la guerra civil, en la que Carteia tomó partido a favor de Pompeyo. El florecimiento de las transacciones comerciales de este centro urbano con el exterior alcanza, asimismo, su cenit en este periodo. La importancia del tráfico comercial entre Carteia y la costa del norte de África puede ser un claro exponente de esta situación. Los estudios numismáticos (Gozalbes 1988) revelan que la mayoría de las monedas de Carteia documentadas en las colonias africanas se enmarcan cronológicamente entre mediados del siglo I a.n.e. y mediados del siglo I d.n.e.

En Baelo Claudia, el inicio de la producción de conservas de pescado se sitúa a fines del siglo II a.n.e, época en la que se documentan los primeros restos atribuibles a una factoría de salazón, alcanzando su mayor apogeo a mediados del siglo I d.n.e., justo cuando se registra además una etapa de intensa actividad constructiva (Domergue 1973; Ponsich 1976).

Por su parte, el alfar de 'El Rinconcillo', según se desprende de los datos aportados por la intervención arqueológica de 1991, tiene una vida productiva enmarcada perfectamente en dicho periodo, y no parece que su origen se encuentre relacionado con la exportación de vinos (a pesar de la tipología de las ánforas producidas), sino de salazón de pescado. De hecho, si como parece indicar la tipología, fuera vino el producto exportado en el segundo tercio del siglo I a.n.e., se plantearían algunos problemas de difícil resolución: el origen de cultivo de los vinos, el punto de destino de los mismos, el limitado alcance de la prohibición del gobierno romano de cultivar vides y olivos en Galia e Hispania en esa época o la identificación de los envases en los que fue exportado el salazón antes del cambio de era, ya que la producción de ánforas Dressel 21-22, presumiblemente destinadas a este fin, es muy limitada.

El desarrollo de una actividad económica susceptible de ser 'capitalizada', con el fin de obtener unos beneficios que difícilmente podían ser adquiridos por medio de la explotación de los recursos agrícolas y/o ganaderos en esta zona, favorecería considerablemente el aumento de la densidad de pequeños asentamientos dispersos, la ampliación de los centros urbanos existentes e, incluso, la fundación de otros nuevos como el de Iulia Transducta, en la segunda mitad del siglo I a.n.e.

\section{Un esquema evolutivo}

Recientemente, a través del estudio de las ánforas de salazón gaditanas de época púnica (FrutosMuñoz 1994) y de hallazgos numismáticos de época ya romana (Chaves-García 1991), se ha sugerido la hipótesis de la existencia en época púnica de un comercio administrado por Gades que controlaba la producción y distribución de la sal, las conservas de pescado y la producción de ánforas para su transporte tanto en la costa gaditana como en la mauritana. Estas ánforas portarían un sello distintivo que indicaría su procedencia y contenido al margen en algunos casos de la tipología de la propia ánfora, 
como ocurre con el caso de un ánfora grecoitálica, tradicionalmente fabricada para transportar el vino de la Campania, hallada en los hornos púnicos de Torre Alta portando un sello alusivo a los procesos de manipulación del pescado.

Estas actividades comerciales, parcialmente detenidas durante el siglo II a.n.e. (Muñoz-FrutosBerriatua 1988), coincidiendo con la etapa de la conquista romana de la Península, parecen revitalizarse a partir de mediados del siglo I a.n.e. y, sobre todo, en los primeros decenios del siglo I d.n.e. con la aparición de nuevos centros productivos, entre los que se encuentran algunos de los situados. en la comarca del Campo de Gibraltar. Al mismo tiempo, las colonias romanas del norte de África, que en época de Augusto dependían administrativamente de la Bética, seguirían dentro del radio de acción de un comercio administrado en la orilla opuesta del Estrecho. Esa dependencia hacia la Península Ibérica, más que del gobierno de África Proconsular, respondería a la antigüedad y frecuencia de las relaciones de los mauritanos con las costas ibéricas (Pavis d'Escurac 1982).

A este respecto se puede retomar la hipótesis de C. Domergue (1973), sobre el significado de las marcas SCC y SCG encontradas en Baelo Claudia y 'El Rinconcillo' tanto en ánforas Dressel 1B-C como Dressel 7-13. La existencia de un monopolio comercial gaditano explicaría el significado atribuido a la primera consonante: $S$ (ocietas). La posibilidad de que se formara una sociedad del garum semejante a la que citan las fuentes para Cartagena no es extraña, puesto que las mayores factorías de salazón se encuentran en el litoral gaditano, así como la mayor densidad de alfares productores de los envases especializados para su comercialización. Probablemente, el origen de la formación de estas sociedades se encuentre en la importancia de la extracción de sal utilizada como medio de cambio y como complemento alimenticio de las poblaciones del interior (Chaves-García 1991) que, posteriormente, se rentabilizaría como conservante (Etienne 1971; Benoit 1959).

Las causas de una posible decadencia del sector a mediados del siglo I d.n.e. en la zona no están muy claras, pero el análisis de algunos acontecimientos producidos a partir de esas fechas puede aportar alguna información interesante a este respecto.

A mediados del siglo I d.n.e. (años 39-43) la Mauritania es conquistada, terminando la dependencia económica que algunas colonias romanas del norte de África tenían respecto a las ciudades costeras de la Bética, entre las que Carteia poseía un lugar destacado (Gozalbes 1988).

No parece que la conquista de la nueva provincia beneficiara a la industria del salazón en ambas orillas, si es que se puede establecer algún tipo de hilo causal entre este hecho y el retroceso productivo que parecen experimentar tanto los emplazamientos industriales de la comarca campogibraltareña como algunos otros de la Mauritania. A este respecto, una de las mayores factorías de salazón conocidas hasta el momento, Lixus, adquiere su época de mayor apogeo entre la segunda mitad del siglo I a.n.e. y principios del siglo I d.n.e., al igual que la de Tahardat (Ponsich 1988).

Es difícil rastrear en los establecimientos urbanos de la costa del Campo de Gibraltar los efectos de este proceso, al haberse centrado fundamentalmente las excavaciones arqueológicas de Carteia o Baelo Claudia en estudios de carácter urbanístico. No obstante se pueden destacar varios indicios que permitirían suponer el impacto negativo que la conquista de la Mauritania supuso para la economía de la zona. En Baelo Claudia, por ejemplo, se advierte una disminución de la actividad económica (Domergue 1973) que si bien se detecta al menos hasta los siglos III y IV, no parece retomar las proporciones adquiridas durante el siglo I. Del mismo modo disminuye la presencia de monedas de Carteia en las ciudades del norte de África (Gozalbes 1988), mientras que la actividad productiva en el alfar de 'El Rinconcillo' cesa durante este periodo.

Estos indicios parecen indicar que, si bien en época de Claudio se alcanzó el punto álgido de las exportaciones béticas tal y como apunta G. Chic (1994), a partir de entonces comienzan a declinar paulatinamente en la segunda mitad del siglo. La conquista de Mauritania, y el proceso de inestabilidad inherente 
a la misma, pudo provocar un cambio en el esquema precedente que no tardaría en deteriorar el marco de relaciones comerciales de la zona de influencia gaditana, especialmente en aquellos lugares en los que la pesca y la salazón de pescado constituían la principal fuente de obtención de recursos económicos.

Las dificultades que existieron en general para las actividades comerciales de la Bética en esta etapa, debieron repercutir doblemente en la producción y exportación de estos productos, dado que requería solventar una situación poco favorable en las aguas del Estrecho no sólo en el momento dar salida al produçto elaborado, sino también a la hora de adquirir la materia prima para su elaboración: el pescado ${ }^{18}$.

Posteriormente, ya en el siglo II d.n.e., se detecta una recuperación de la industria que vuelve a recaer definitivamente en el siglo III a causa de la crisis económica general que desmoronaba definitivamente los cimientos del estado imperial romano. La crisis del siglo III no comportó la desaparición de las actividades económicas relacionadas con la pesca y las conservas de pescado. De hecho, en algunas factorías de salazón se documenta una actividad productiva que, en algunos casos, a juzgar por el material hallado en superficie, se extiende hasta los siglos V y VI d.n.e., como sería el caso de Getares (Algeciras, Cádiz), Tarifa (Cádiz), Venta del Tito (Tarifa, Cádiz), Mellaria (Tarifa, Cádiz), Cortijo del Pozuelo (Tarifa, Cádiz), etc. (Ponsich 1988).

Sin embargo, estas factorías abastecerían ahora a un mercado local, no alcanzado en ningún momento los niveles productivos adquiridos entre mediados del siglo I a.n.e. y mediados del siglo I d.n.e.. En este periodo se operó un desarrollo de la industria y el comercio en el Campo de Gibraltar basado en la explotación de los recursos marinos que, hasta la implantación de las industrias petroquímicas en la Bahía de Algeciras, ha constituido tradicionalmente el sector más pujante de la economía campogibraltareña.

\section{La especialización en el trabajo: un sector 'protoindustrializado'}

Un último aspecto relevante se refiere al grado de especialización de la mano de obra necesaria para completar el ciclo productivo relacionado con la actividad pesquera en época romana. Esta especialización no se refiere sólo a las distintas actividades que se ven implicadas en la explotación de los recursos pesqueros, es decir, pescadores, extractores de sal, trabajadores de las factorías de salazón, alfareros y comerciantes, sino que dentro de cada una de estas categorías se requería una formación especializada en cada fase del proceso.

M. Ponsich $(1976 ; 1988)$ describe la jerarquía existente entre las personas que participaban en las labores de captura del pescado, desde los capitanes de almadraba hasta los trabajadores sin especialización pasando por los jefes de pesca y los acechadores. En las fábricas de salazón esta división del trabajo también se hacía patente con la existencia de cortadores de pescado, fabricantes de garum, fogoneros, mantenedores, etc.

En muchas alfarerías peninsulares esta especialización también debió existir, al igual que la jerarquización en el reparto de un trabajo que requería cuanto menos un mínimo aprendizaje previo para adquirir los conocimientos técnicos que requiere la utilización de un torno, o el tratamiento y cocción de las cerámicas. De hecho, Comfort (Martino 1985) ha indicado la presencia de tres categorías de obreros dentro de un alfar, los que hacían los modelos, los que hacían los recipientes y otros encargados de tareas imprecisas, al frente de todos los cuales se encontraría el maestro. Esta división del trabajo,

18. Estas dificultades quizá no se hicieron tan patentes en la zona levantina donde factorías que comienzan su producción en época tardorrepublicana como la de Punta de l'Arenal tienen todavía unos altos niveles de producción en el siglo II d.n.e. (Martín 1970). 
más o menos acentuada dependiendo de la envergadura del alfar, distancia lo que podría considerarse un taller artesanal de una verdadera fábrica, cambio cualitativo que se opera inicialmente en base a la existencia de una demanda masiva del mercado ${ }^{19}$, supuesto que existía sin lugar a dudas en la producción cerámica y de objetos de vidrio (Martino 1985: 386).

Por otra parte, si se aceptan aproximativamente los cálculos realizados por Pascual Guach (1968), el volumen de ánforas que debía producir un alfar para abastecer a una factoría de salazón como Lixus (excavada sólo en parte y suponiendo que las piletas sólo se llenaran una vez al año) era de unos 78.000 ejemplares al año. Presuponiendo que cada alfar podría abastecer a más de una factoría de salazón, además de producir otros tipos anfóricos destinados a la comercialización de diferentes productos, el volumen de producción anual convertiría a estos centros en verdaderas fábricas de carácter 'protoindustrial' más que artesanal.

Si bien actualmente no hay datos concluyentes acerca del tipo de mano de obra empleada en las labores propias de la alfarería de 'El Rinconcillo' (libre o esclava) o de la propiedad de la misma, las excavaciones llevadas a cabo en el alfar sí parecen ofrecer alguna información referida al proceso de producción.

La existencia de un pequeño horno en el que se ha denominado 'Sector 3' de dicho alfar, empleado exclusivamente para la producción de pequeñas tapaderas de ánforas, presupone la existencia de una especialización de la producción y, derivado de ello, del trabajo dentro de la alfarería, aunque, a falta de excavaciones más sistemáticas, no se pueda afirmar con rotundidad que se rebasaron los límites del taller artesano.

Este cambio, no sólo cuantitativo sino también cualitativo, puede rastrearse asimismo en la propia actividad pesquera que en época romana no puede encuadrarse totalmente en las categorías 'tradicional' o 'artesanal' definidas por J. Benito Arranz (1993), aunque estas sin duda hayan existido en mayor o menor medida. Por el contrario, el volumen de materia prima necesario para rentabilizar las factorías de salazón de la costa del Estrecho de Gibraltar y el alto grado de coordinación que debió existir entre pescadores, factorías, alfares y comerciantes para articular la exportación a larga distancia de los productos piscícolas (Curtis 1988), permite suponer la existencia de una actividad pesquera más cercana a la de carácter 'industrial' que a la artesanal. D.P.S. Peacock (1975) incluso ha llegado a determinar a través de un estudio petrológico de algunas ánforas de salazones de la provincia de Cádiz y de otras del mismo tipo halladas en excavaciones en Gran Bretaña, que la mayor parte de las conservas de pescado que se importaban en Britania se envasaban en ánforas procedentes de hornos cercanos a Cádiz, y en menor medida del alfar de 'El Rinconcillo'.

De este modo, se constata por primera vez en la comarca del Campo de Gibraltar, ya que el registro arqueológico de épocas pre y protohistórica es muy débil, la existencia de una actividad productiva que, a raíz del aumento de la demanda de productos derivados del pescado, produce un salto cualitativo en la naturaleza del proceso de producción en aquellas actividades económicas asociadas a la elaboración y comercialización de productos derivados del pescado, si bien la falta de suficiente información con respecto a la distribución del trabajo y de las características de la mano de obra y su relación con los medios de producción, dificulta el establecimiento de paralelismos fiables con otros modelos de producción de épocas tanto anteriores como posteriores.

19. "Si queremos enjuiciar de modo realista el problema de las dimensiones industriales, no son los procesos técnicos ni la división y especialización del trabajo los que aparecen en primer plano, sino el mercado, y éste sólo era amplio para el consumo masivo" (Martino 1985: 386) 


\section{BIBLIOGRAFÍA}

ALMAGRO, M. (1983): "Colonizzazione e acculturazione nella penisola iberica" Forme di contatto e processi di trasformazione nelle societá antiche. Ecole Française de Rome. Pisa-Roma. Pgs.: 329-461. ARTEAGA, O. (1985): "Excavaciones arqueológicas en el Cerro del Mar (Campaña de 1982)" Noticiario Arqueológico Hispánico 23. Ministerio de Cultura. Pgs: 196-233

ARTHUR, P. y RICCI, A.: (1983): "Sistemi di quantificazione della ceramica proveniente da scavi di complessi di epoca romana." Dialoghi di Archeologia. Pgs.: 125-128.

BARCELÓ, A. (1985): "Historia y teoría económica" En AA.VV.: Hacia una nueva historia. Akal/Universitaria. Madrid. Pgs.: 35-58

BELTRÁN, M. (1977): "Problemas de la morfología y del concepto histórico-geográfico que recubre la noción tipo" Méthodes classiques et méthodes formelles dans l'étude des amphores. Roma. Pgs.: 97-130

BENITO, J. (1993): “Un capítulo de la humanización del espacio acuático: la pesca” Espacio y Tiempo. Revista de Ciencias Humanas, 7. Pgs.: 9-21

BENOIT, F. (1959): "L'économie du litoral de la Narbonnaise à l'époque antique: le commerce du sel et les pêcheries" Rivista di Studi Liguri XXV. Numeri 1-2. Istituto Internazionale di Studi Liguri. Pgs.: 87-110

BUENO, M. (1988): El Renacer de Algeciras (a través de los viajeros). Algeciras.

CARANDINI, A. (1980): "Roma imperialistica: un caso di sviluppo precapitalistico" Memoirs of the American Academy in Rome. Vol. XXXVI. Rome. Pgs.: 11-19.

(1981): "Sviluppo e crisi delle manifatture rurali e urbane" Società romana e produzione schiavistica II. Bari. Pgs: 249-260

(1989): "L'economia italica fra tarda republica e medio imperio considerata dal punto di vista di una merce: il vino". Amphores romanes et histoire economique. Collection de l'Ecole Française de Rome, 114. Rome. Pgs.: 529-536.

CARANDINI, A. (ed) (1985): Setefinestre, una villa schiavistica nell'Etruria romana. Modena.

CARANDINI, A. et allii (1973): Ostia III. Le terme del Noutatore. Scavi degli ambienti III, VI, VII. Seminario di Archeologia e Storia dell'Arte Greca e Romana dell'Università di Roma. Roma.

CASTRO, J.- GUERRA, A. y FABIAO, C. (1991): "As lucernas do acampamento militar romano da Lomba do Canho (Arganil)" Conimbriga, 29. Pgs.: 69-90

CURTIS, R.I.: (1979): The production and commerce of fish sauce in the western roman empire. A social and economic study. University of Maryland. Phyladelphia.

- (1988): "Spanish trade in salted fish products in the 1st and 2nd centuries AD" The International Journal of Nautical Archaeology and Underwater Exploration 17.3. Pgs.: 205-210.

CHAVES, F. y GARCÍA, E. (1991): "Reflexiones en torno al área comercial de Gades: Estudio numismático y económico" Gerión, 9. Pgs.: 139-168

CHIC, G. (1984): Cádiz: Historia Antigua. Provincia de Cádiz. Editorial Geuer. Sevilla

— (1985): "Aspectos económicos de la Política de Augusto en la Bética". Habis, 16. Universidad de Sevilla. Sevilla. Pgs.: 277-300.

_ (1991): "Economía Política en época de Tiberio. Su reflejo en la Bética". Laverna II. Pgs.: 76- 128. (1994): La proyección económica de la Bética en el Imperio Romano (época altoimperial).

Biblioteca Económica de Cultura Ecuménica. Padilla Libros. Sevilla 
DOMERGUE, C. (1969): "Le campagne de fouilles 1966 à Bolonia (Cádiz)" X Congreso Nacional de Arqueología. Mahón, 1967. Zaragoza. Pgs.: 442-456.

— (1973): Belo I. La stratigraphie. Publications de la Casa de Velázquez. Série "Archeologie". Tomo 1. Paris.

DYSON, S.L. (1989): "Complacency and crisis in late twentieth century classical archaeology" En CULHAM, P.- EDMUNDS, L. (eds): Classics: a discipline and profession in crisis. University Press of America. New York. Pgs.: 211-220

(1993): "From New to New Age Archaeology: Archaeological Theory and Classical Archaeology A 1990s Perspective". American Journal of Archaeology 97. Pgs.: 195-206

ESPINOSA, U. (1988): "Riqueza mobiliaria y promoción política; los Mamili de Tritium Magallum" Gerión, 6. Editorial de la Universidad Computense de Madrid. Pgs.: 263-272

ETIENNE, R. (1971): “A propos du 'garum sociorum"” Actas de la I Reunión de Historia de la Economía Antigua de la Península Ibérica. 11-13 Enero, 1969. Anales de Arqueología de Valencia. Valencia. Pgs.: 297-313

FABIAO, C. (1987): "Anforas romanas republicanas de um depósito de Mértola no Museu Nacional de Arqueologia Etnologia" O Arqueólogo Português, Serie IV, 5. Pgs.: 125-148

FERNÁNDEZ, S. (1994): El Campo de Gibraltar en la Antigüedad: Una aproximación arqueológica a la estructura económica de un territorio integrado. Tesis de Licenciatura. Sevilla. Inédito.

(1995): "Excavaciones arqueológicas en El Rinconcillo (Algeciras, Cádiz)" Anuario Arqueológico de Andalucía, 1992. Junta de Andalucía. Sevilla. En prensa.

FERNÁNDEZ, S. y GARCÍA, L. (1995): “Clásica Arqueología, Antigua Historia. Ensayo en torno a un desencuentro en la tradición historiográfica de Andalucía Occidental”. Spal, 2. Departamento de Prehistoria y Arqueología. Universidad de Sevilla. Sevilla. Pgs.: 57-79.

FIRPO, L (ed) (1980): "Il pensiero economico dei Romani". Storia delle idee politiche, economiche e sociali. Vol.I, UTET. Turín. Pgs: $877-960$.

FRUTOS, G. y MUÑOZ, A. (1994): "Hornos púnicos de Torre Alta (San Fernando, Cádiz)" En CAMPOS, J.- PÉREZ, J.A. y GÓMEZ, F. (eds): Arqueología en el entorno del Bajo Guadiana. Actas del Encuentro Internacional de Arqueología del Suroeste (Huelva, Marzo 1993). Huelva.

GABBA, E. (1980): "Reflessione antiche e moderne sulle attività commerciali a Roma nei secoli II e I a. C." Memoirs of the American Academy in Rome XXXVI. Rome. Pgs: 91-101.

GÓMEZ, A.- FERNÁNDEZ, S. y POLVORINOS, A. (1995): "Roman Ceramics Production and Archeometry in Algeciras (Cádiz, Spain)". The Cultural Ceramic Heritage. $3^{\text {rd }}$ European Meeting on Ancient Ceramics. Archaeometric and Archaological Studies. Riccione (Italy) October 2-4. Pgs.: 257-267.

GOZALBES, E. (1988): "Carteia y la región de Ceuta. Contribución al estudio de las relaciones entre ambas orillas del Estrecho en la Antigüedad Clásica" Congreso Internacional 'El Estrecho de Gibraltar'. Ceuta-Noviembre, 1987. Tomo I. Madrid. Pgs.: 1047-1067.

GUERRA, A. y FABIAO, C. (1988): "Escavaçoes no campamento romano da Lomba do Canho (Arganil): Resultados preliminares" Actas ler Congreso Peninsular de Historia Antigua. Vol. 1. Universidad de Santiago de Compostela. Pgs.: 307-328

- (1989): Sobre as ánforas do acampamento romano da Lomba do Canho (Arganil). INIC-UNIARC.

HALEY, E.W. (1988): "Roman elite involvement in commerce: the case of the spanisc TT. Mamilii" Archivo Español de Arqueología, 61. Pgs.: 141-156 
HESNARD, A. (1980): "Un dêpot augustéen d'amphores à la Longarina. Ostie" Memoirs of American Academy of Rome 36. Roma. Pgs.: 141-156

LAMBOGLIA, N. (1955): "Sulla cronología delle anfore romane ni età repubblicana (II-I secolo a.C.)" Rivista di Studi Liguri XXI. Pgs.: 241-270.

(1974): "I rapporti fra l'Italia e la Spagna attraverso la ceramica".Colloquio Italo-Spagnolo sul tema: Hispania Romana (Roma 15-16 maggio 1972). Accademia Nazionale dei Lincei. Roma. Pgs.: 39-45.

(1979): Gli scavi di Albintimilium e la cronologia della ceramica romana. Bordighera.

LAUBENHEIMER, F. (1980): “A propos de Deux Amphores de Ruscino: Definition d'un Nouveau Type d'Amphores" En BARROUL, G. (dir): Ruscino I. París. Pgs.: 303-325

LIOU, B. (1990): "Le commerce de la Bètique au 1er siècle de notre ére. Notes sur l'epave Lavezzi 1 (Bonifacio, Corse du Sud)" Archaeonautica 10. Pgs.: 125-147

LIOU, B. y DOMERGUE, C. (1990): "Le commerce de la Betica au ler siècle de notre ere. L'epave Sud-Lavezzi 2 (Bonifacio, Corse du Sud)" Archaeonautica 10. Pags.: 12-45

LUSUARDI, S. (1977a): "Appunti su alcuni tipi di anfore lunensi". Méthodes classiques et méthodes formelles dans l'étude typologique des amphores (Rome 27-29 mai 1974). Ecole Française de Rome. Pgs.: 207-230

- (1977b): Scavi di Luni II. Roma

MADOZ, P. (1990): Diccionario geográfico-estadístico-histórico de España y sus posesiones de Ultramar. Ambito. Editoriales Andaluzas Unidas. Salamanca. (1 $1^{a}$ Edición: Madrid, 1847).

MANACORDA, D. (1977): “Anfore spagnole a Pompei”. L'Instrumentum domesticum di Ercolano e Pompei. Cuaderni di Cultura Materiale I. Pgs.: 121-133.

MARÍN, N. y PRIETO, A. (1987): "Observaciones sobre la forma de producción y circulación del vino de la provincia romana de la Betica" El vi a l'Antiquitat. Economia, producció i comerç al Mediterrani Occidental. Actes I Coloqui d'Arqueologia Romana. Badalona, 28-29-30 noviembre-1 diciembre, 1985. Pgs.: 369-375

MARTíN, G. (1970): "Las pesquerías romanas de la costa de Alicante" Papeles del Laboratorio de Arqueología de Valencia, X. Pgs.: 139-153.

MARTINO, F. de (1985): Historia económica de la Roma Antigua. Akal/Universitaria. Madrid

MORALES, A. y ROSELLÓ, E. (1988): "La riqueza del Estrecho de Gibraltar como inductor potencial del proceso colonizador en la Península Ibérica" Congreso Internacional "El Estrecho de Gibraltar" Ceuta-Noviembre, 1987. Tomo IV. Madrid. Pgs.: 447-457

MOREL, J.P. (1983): "Les relations economiques dans l'occidente grec" Forme di contatto e processi di trasformazione nella societá antiche. Pise-Rome. Pgs.: 549-580.

_ (1985): "La manufacture, moyen d'enrichissement dans l'Italia Romaine" L'origine des richesses depensées dans la ville antique. Actes du colloque. Aix-en-Provence 11-12 mai 1984. Aix-enProvence. Pgs: 87-111.

MUÑOZ, A.-DE FRUTOS, G y BERRIATÚA, N. (1988): “Contribución a los orígenes y difusión comercial de la industria pesquera y conservera gaditana a través de las recientes aportaciones de las factorías de salazones de la Bahía de Cádiz" Congreso Internacional "El Estrecho de Gibraltar" Ceuta-Noviembre, 1987. Tomo I. Madrid. Pgs.: 487-508

MUSTI, D. (1984): "Aspetti economici et aspetti politici dell'espansione romana nella storiografia Polibiana". Papers and Monographs of the American Academy in Roma. Volume XXIX. American Academy in Roma. Roma. 
PANELLA, C. (1981): "La distribuzione e i mercati" En GIARDINA, A.- SCHIAVONE, A. (Eds.): Società romana e produzione schiavistica. Merci, mercati e scambi nel Mediterraneo. Editori Laterza. Bari. Pgs.: 55-80.

PASCUAL GUASCH, R. (1968): “Acerca de la fabricación de ánforas” Ampurias LXXX. Barcelona. Pgs.: 237-248.

- (1980): "La evolución de las exportaciones béticas durante el Imperio" Producción y comercio del aceite en la Antigüedad. Primer Congreso Internacional. Universidad Complutense. Madrid. Pgs: 233-242.

PAVIS D'ESCURAC, H. (1977): “Aristocratie sénatoriale et profits commerciaux" Ktema, 2. Pgs.: 339-355 — (1982): "Les méthodes de l'imperialisme romain en Murétanie de 33 avant J.C. à 40 aprés J.C." Ktema, 7. Pgs.: 221-233

PEACOCK, D.P.S. (1975): "Amphorae and the Baetican fish industry" The Antiquaries Journal. Vol. LIV. Part II. Pgs.: 232-243

PONSICH, M. (1976): “A propos d'une usine antique de salaisons a Belo (Bolonia, Cadix)" Melánges de la Casa de Velazquez. Tome XII. Pgs.: 69-79.

(1988): Aceite de oliva y salazones de pescado. Factores geo-económicos de la Betica y Tingitania. Universidad Complutense. Madrid.

PONSICH, M. y TARRADELL, M. (1965): Garum et industries antiques de salaison dans la Méditerranée Occidentale. Paris.

PRESEDO, F. (1982): Carteia I. Archivo Español de Arqueología. Madrid.

- (1987a): "Informe de la campaña arqueológica de 1985 en el yacimiento de Carteia (San Roque, Cádiz). Anuario Arqueológico de Andalucía, 1985. Tomo II. Junta de Andalucía. Sevilla. Pgs.: 387-393.

_. (1987b): "Memoria sucinta de las excavaciones de Carteia" Anuario Arqueológico de Andalucía, 1986. Tomo II. Dirección General de Bienes Culturales. Sevilla. Pgs.: 450-457.

PRESEDO, F. y CABALLOS, A. (1988): "La ciudad de Carteia: estado de la cuestión y primeros resultados de la campaña de 1985" Actas del ler Congreso Peninsular de Historia Antigua. Julio, 1986. Universidad de Santiago de Compostela. Santiago de Compostela. Pgs.: 509-519.

PUCCI, G. (1985): "Città ed economia in età romana: qualche riflessione" L'origine des richesses depensées dans la ville antique. Actes du colloque. Aix-en-Provence 11-12 mai 1984. Aix-en Provence. Pgs.: 275-280.

RICCI, M. (1973): "Per una cronologia delle lucerne tardo-republicane" Rivista di Studi Liguri, 39. Pgs.: 168- 234.

RIPOLL, S. (1988): "El atún en las monedas antiguas del Estrecho y su simbolismo económico y religioso" Congreso Internacional "El Estrecho de Gibraltar" Ceuta-Noviembre, 1987. Tomo I. Madrid. Pgs.: 481-485

RODRÍGUEZ OLIVA, P. (1977): "La arqueología romana de Algeciras (Cádiz)” Segovia. Symposium de Arqueología romana. Publicaciones Eventuales $n^{\circ} 27$. Instituto de Arqueología y Prehistoria. Universidad de Barcelona. Barcelona. Pgs.: 345-349

ROSELLÓ, E. y MORALES, A. (1988): "Ictiofaunas de yacimientos costeros ibéricos: patrones de agrupamiento con ayuda de técnicas multivariantes e implicaciones paleoculturales" Congreso Internacional "El Estrecho de Gibraltar" Ceuta, noviembre, 1987. Tomo IV. Madrid. Pgs.: 459-472.

ROSTOVTZEFF, M. (1981): Historia social y económica del Imperio Romano. Espasa-Calpe. Madrid. [1ª Edición 1937].

SÁEZ, P. (1987): Agricultura romana de la Bética. Gráficas Sol. Écija. 
SILLIERES, P. (1988): "Les villes antiques du littoral septentrional du détroit de Gibraltar" Congreso Internacional 'El Estrecho de Gibraltar'. Ceuta-Noviembre, 1987. Tomo I. Madrid. Pgs: 791-799.

SNODGRASS, A.M. (1985): "The New Archaeology and the Classical Archaeologist" American Journal of Archaeology 89. Pgs.: 31-37

SOTOMAYOR, M. (1967): "Hornos romanos de ánforas en Algeciras" X Congreso Nacional de Arqueología. Zaragoza. Pgs.: 389-399

SYME, R. (1977): "La richesse des aristocraties de Bétique et de Narbonnaise" Ktema, 2. Pgs.: 373-379

TCHERNIA, A. (1987): "Modèles économiques et commerce du vin à la fin de la république et au début de l'empire" El vi a l'Antiquitat. Economia, producció $i$ comerç al Mediterrani Occidental. Actes I Coloque d'Arqueologia Romana. Badalona, 28-29-30 novembre, 1 decembre 1985. Barcelona. Pgs.: 327-336

THIERRIN-MICHAEL, G. (1995): "Production of italic wine amphorae: some technical aspects" The Cultural Ceramic Heritage. $3^{\text {rd }}$ European Meeting on Ancient Ceramics. Archaeometric and Archaological Studies. Riccione (Italy) October 2-4. Pgs.: 173-183.

VALENCIA, M. (1991): Agricultura, comercio y ética. Ideología económica y economía en Roma (II a.e.- I d.e.) Departamento de Ciencias de la Antigüedad. Universidad de Zaragoza. Zaragoza, 1991.

VEGAS, M. (1973): Cerámica común romana del Mediterráneo Occidental. Publicaciones Eventuales $n^{\circ}$ 22. Universidad de Barcelona. Instituto de Arqueología y Prehistoria. Barcelona.

WILL, E.L. (1979): "The Seistius Amphoras: a Reapraisal" Journal of Field Archaeology, 6. Pgs.: 339-350 (1987): “The Roman Amphoras" En McCann, A.M. (Ed.): The Roman Port and Fishery of Cosa. Princeton University Press. Princeton. Pgs.: 171-220

ZEVI, F. (1966): "Apunti sulle anfore romane" Archeologia Clasica 18, 1. Pgs.: 229-230. 


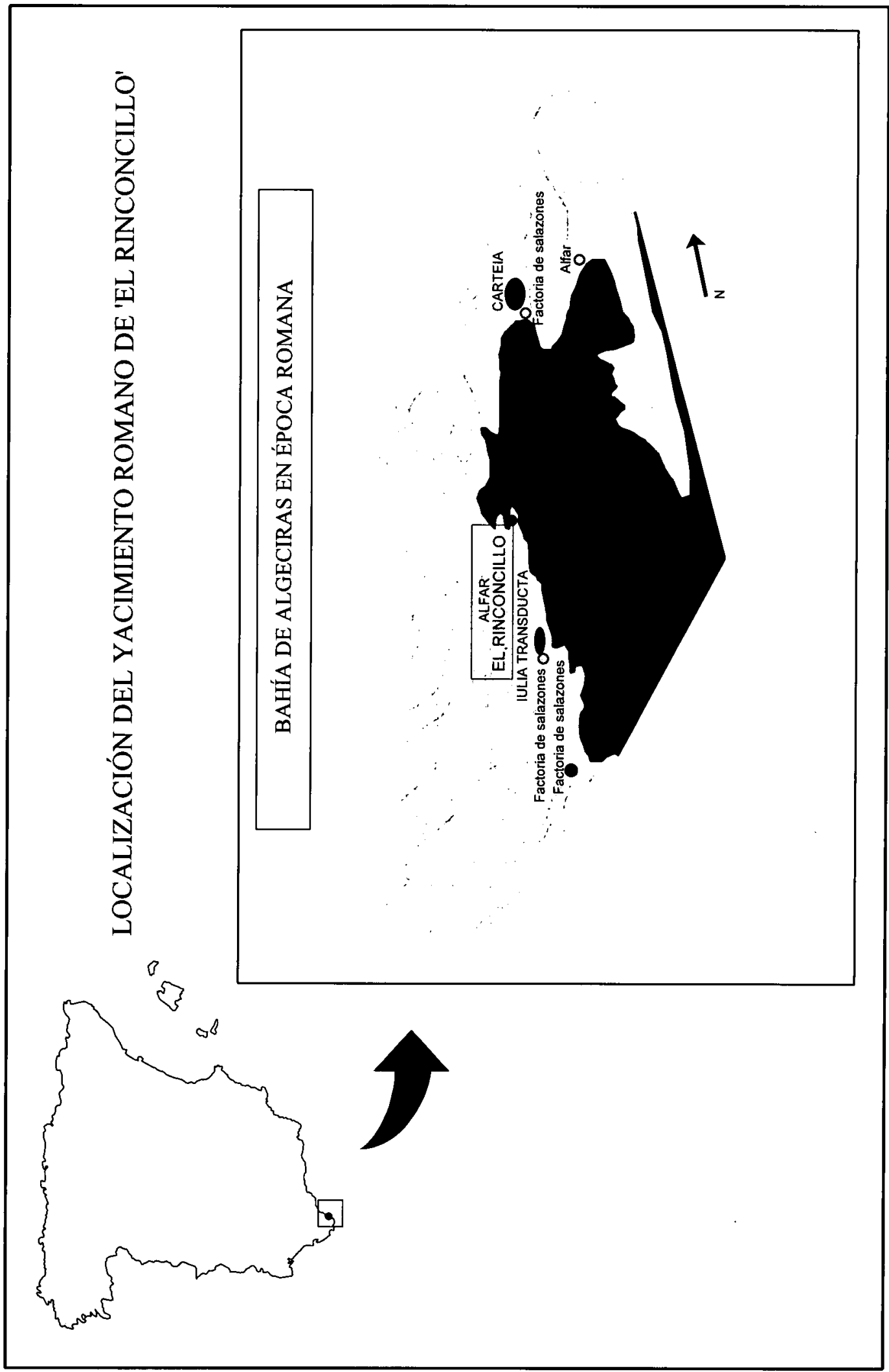

ISSN: 1133-4525 ISSN-e: 2255-3924

http://dx.doi.org/10.12795/spal.1995.i4.07 


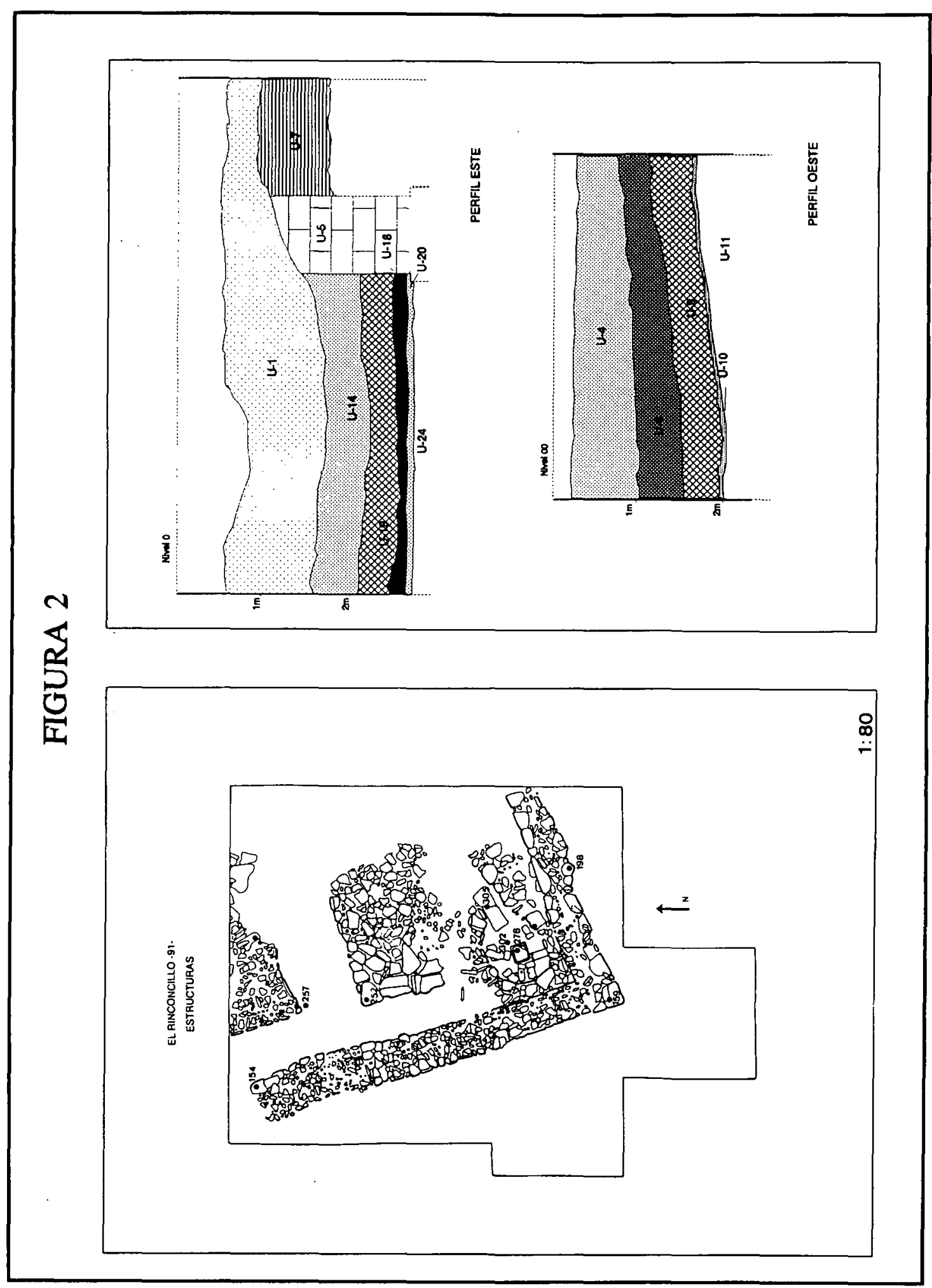




\section{FIGURA 3}

\section{FASE II}

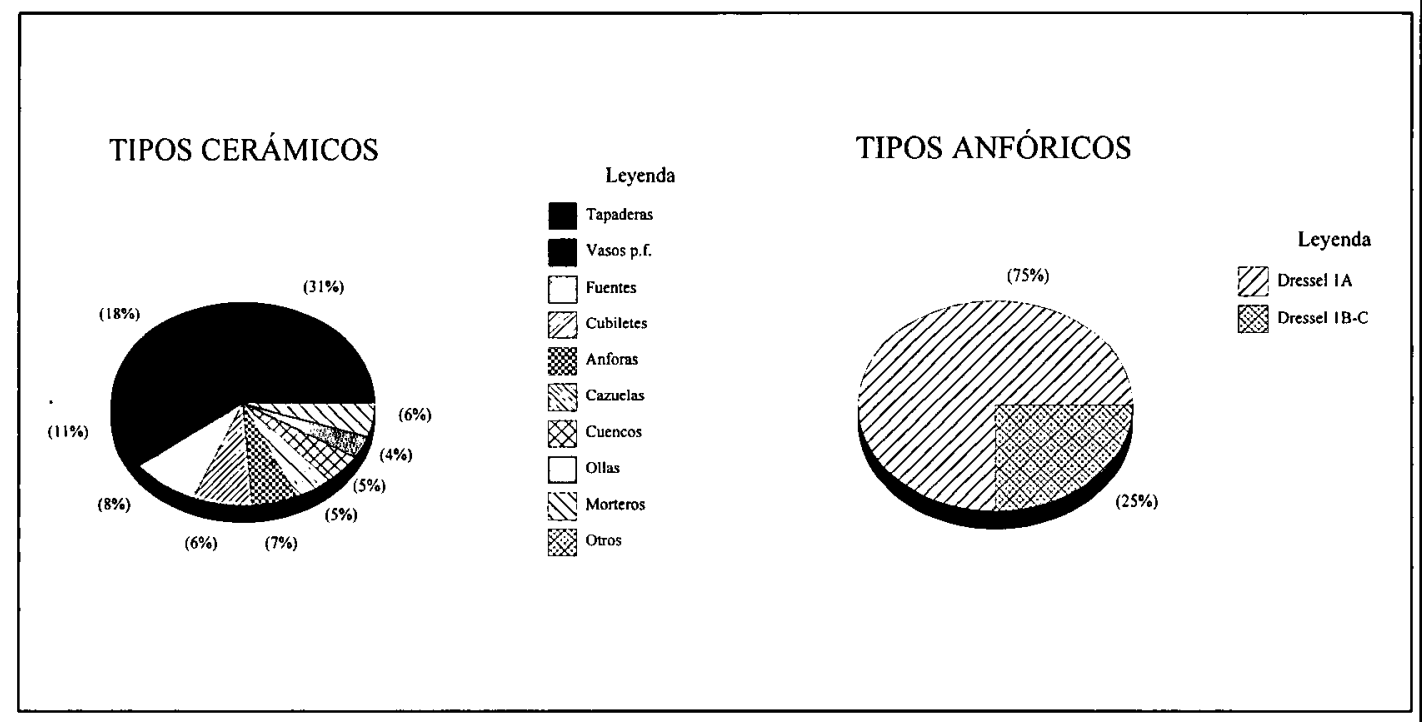

FASE III

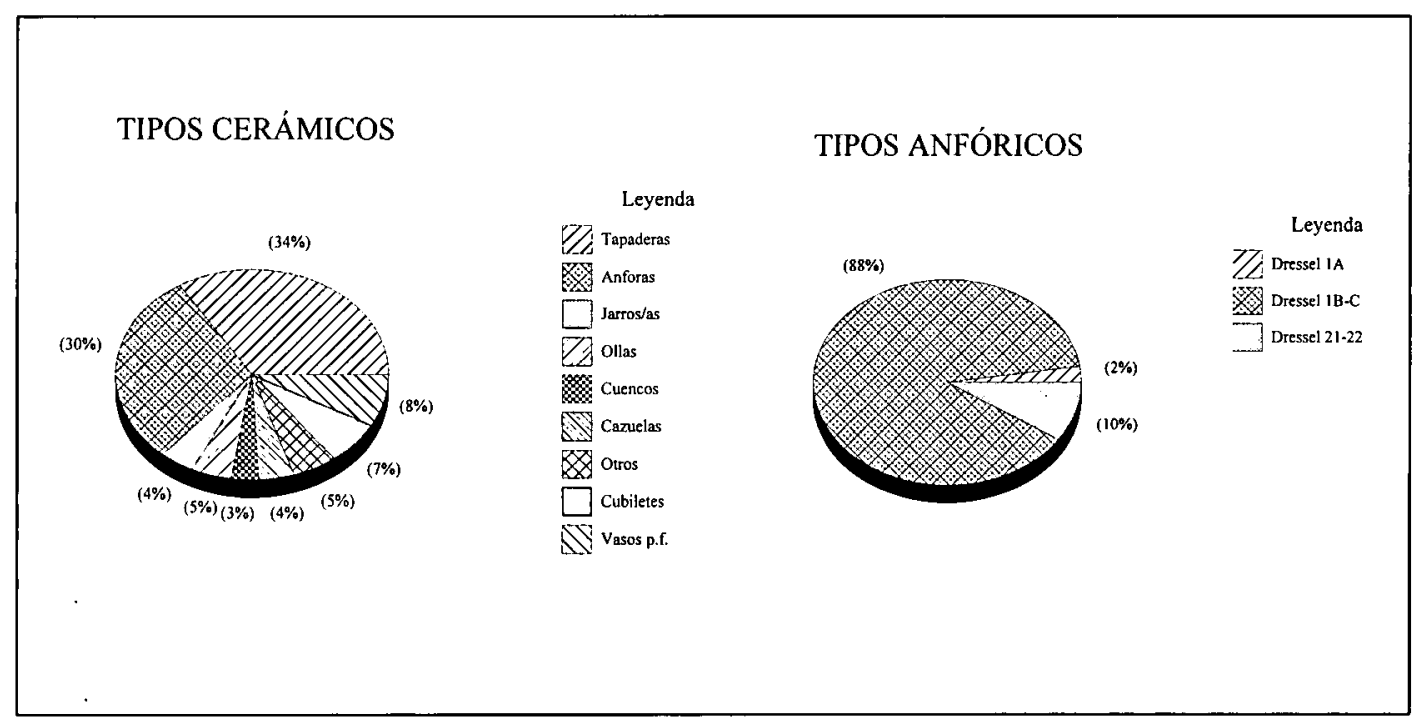




\section{FIGURA 4}

\section{FASE IV}

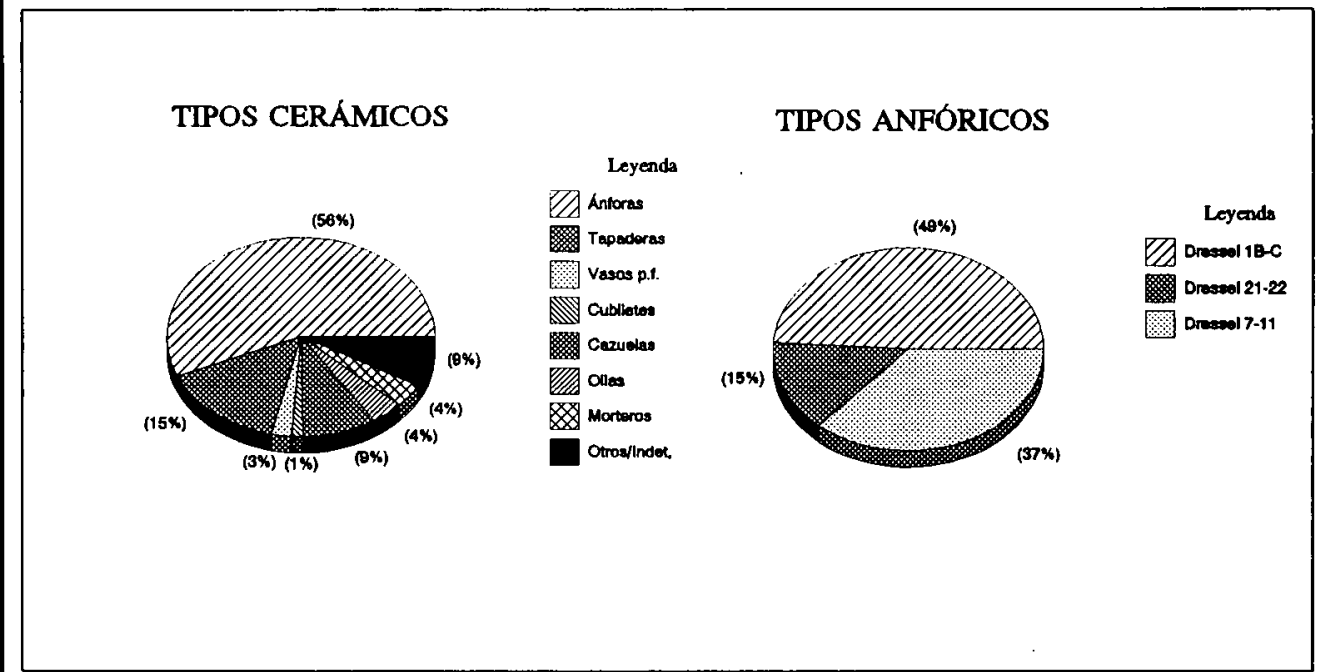

FASE V

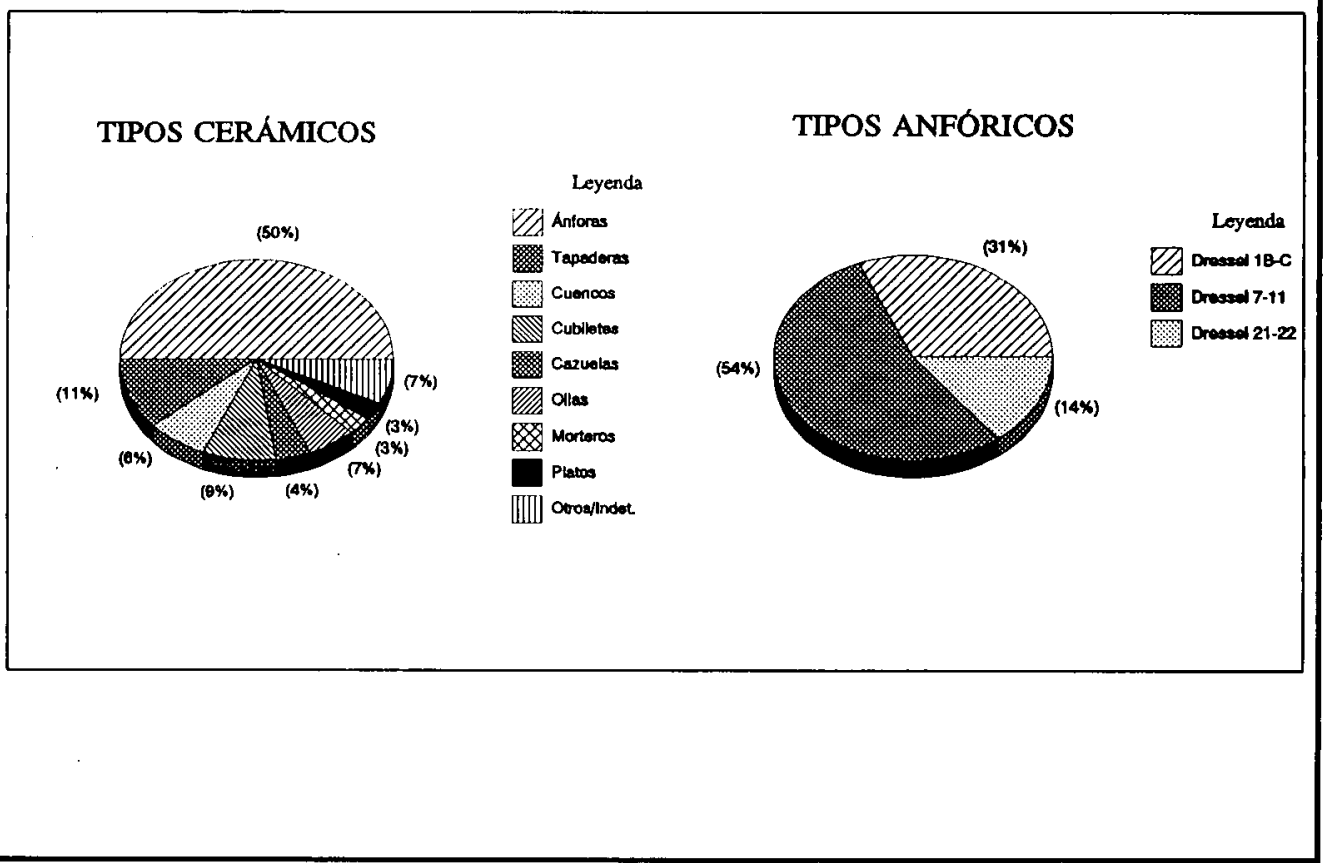




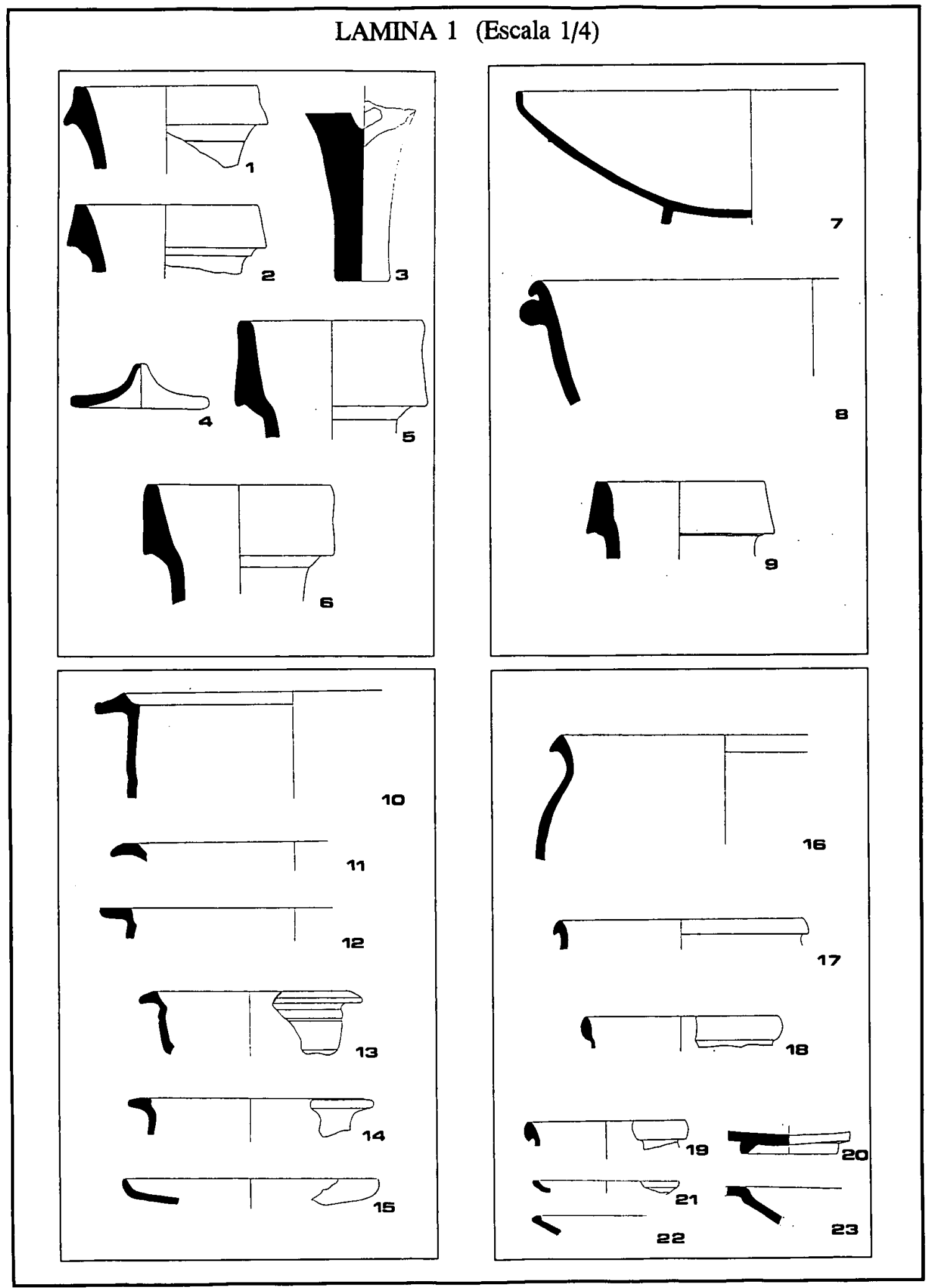

ISSN: 1133-4525 ISSN-e: 2255-3924 


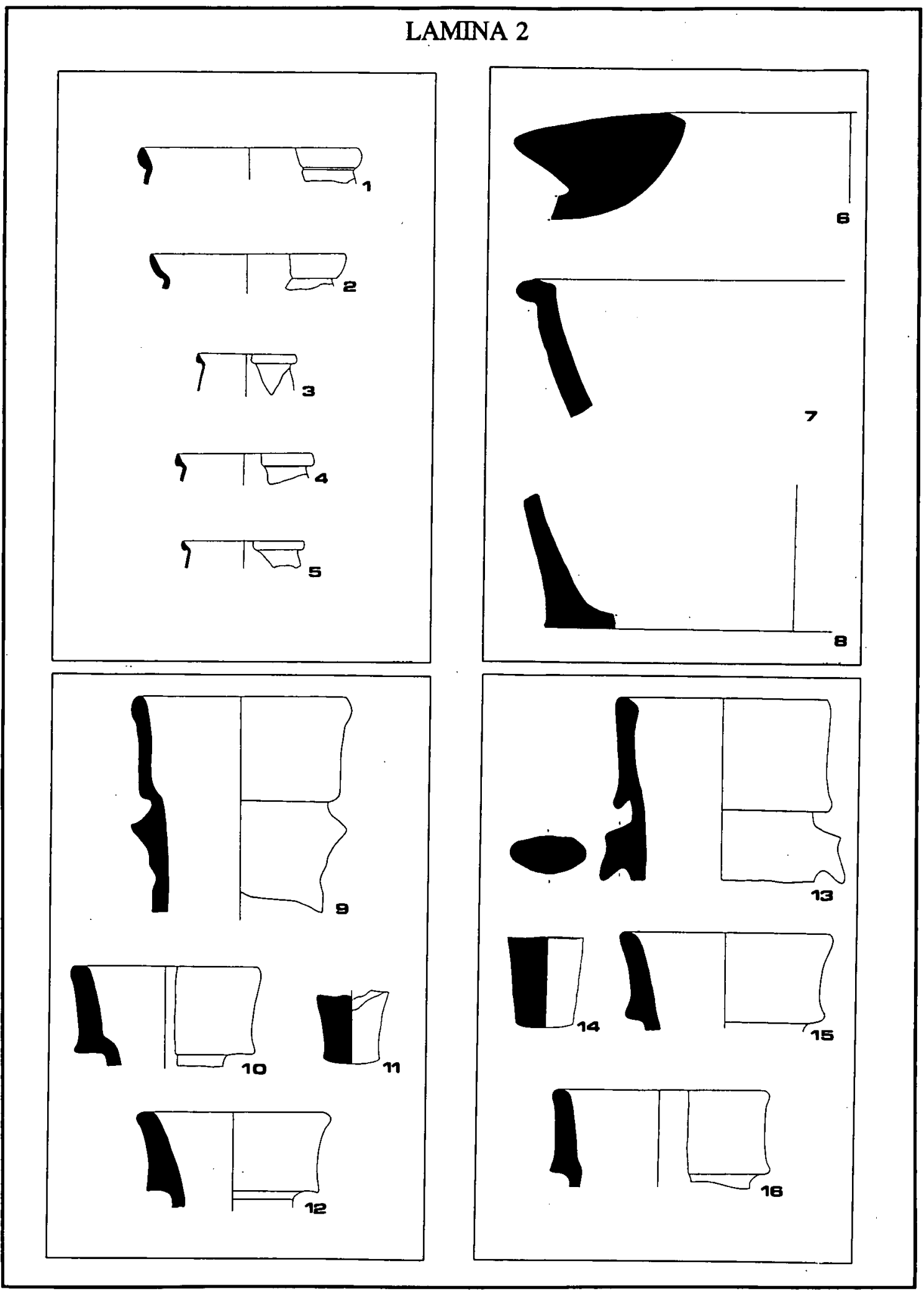




$$
11
$$




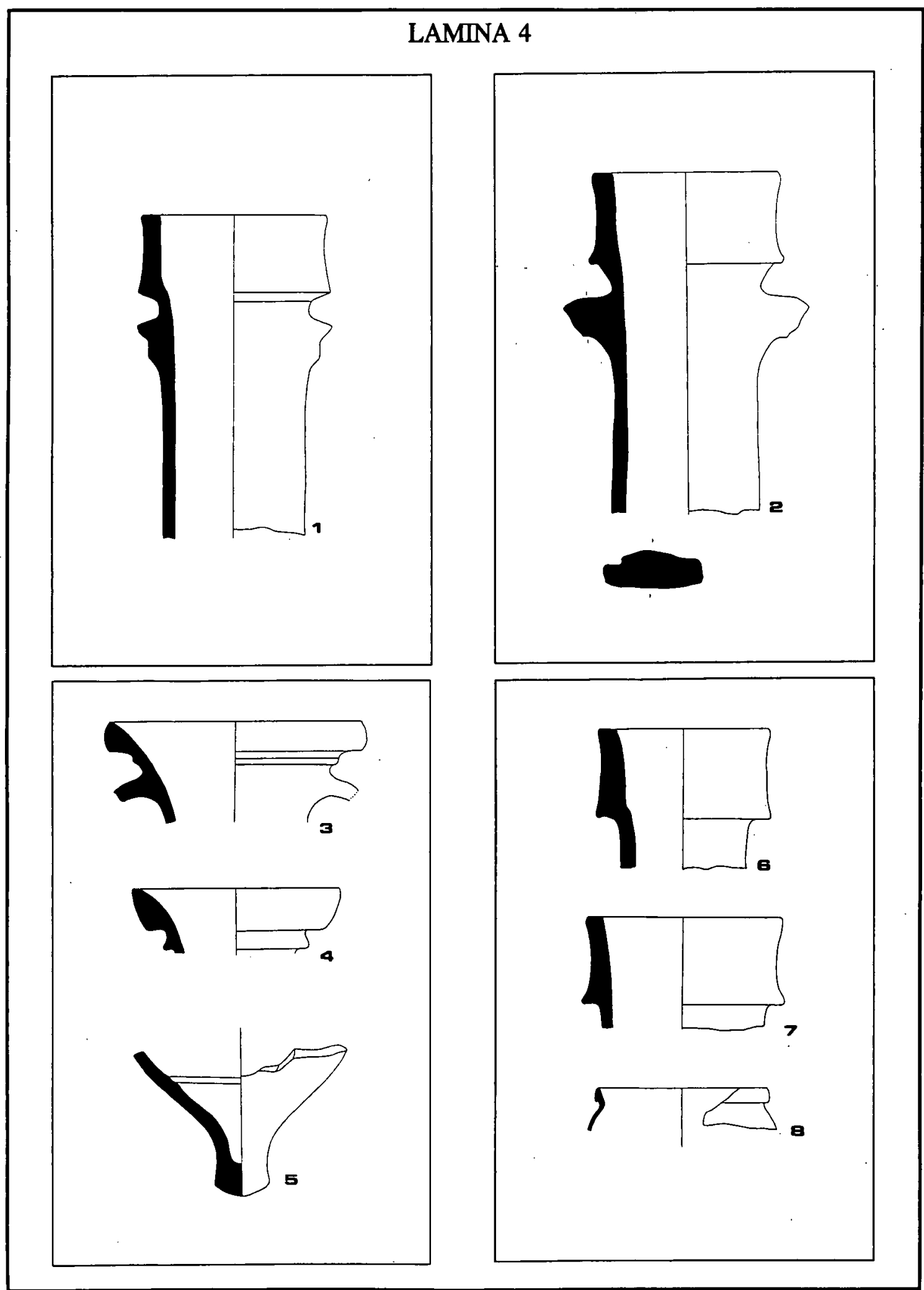




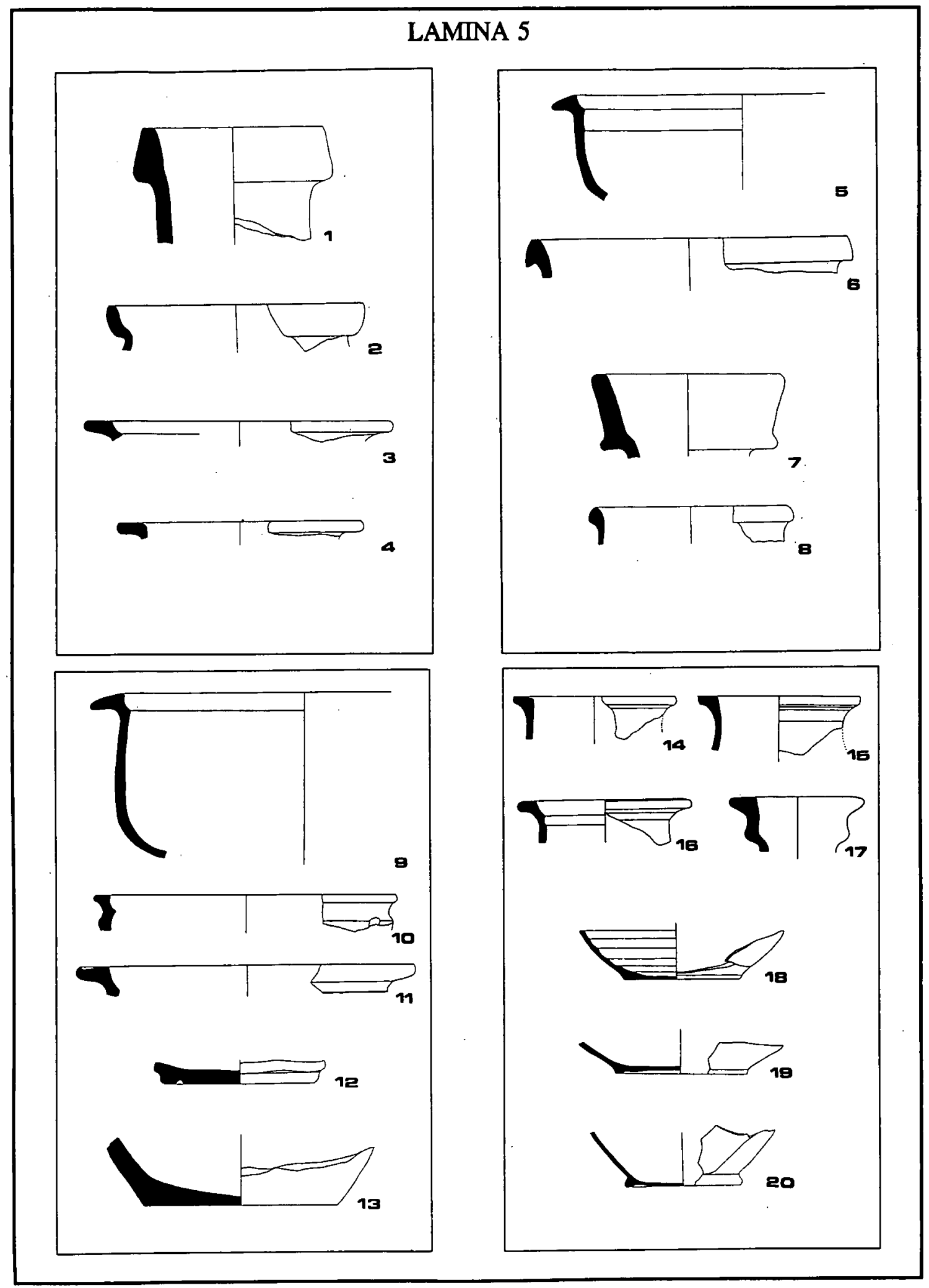

ISSN: 1133-4525 ISSN-e: 2255-3924

SPAL 4 (1995)

http://dx.doi.org/10.12795/spal.1995.i4.07 


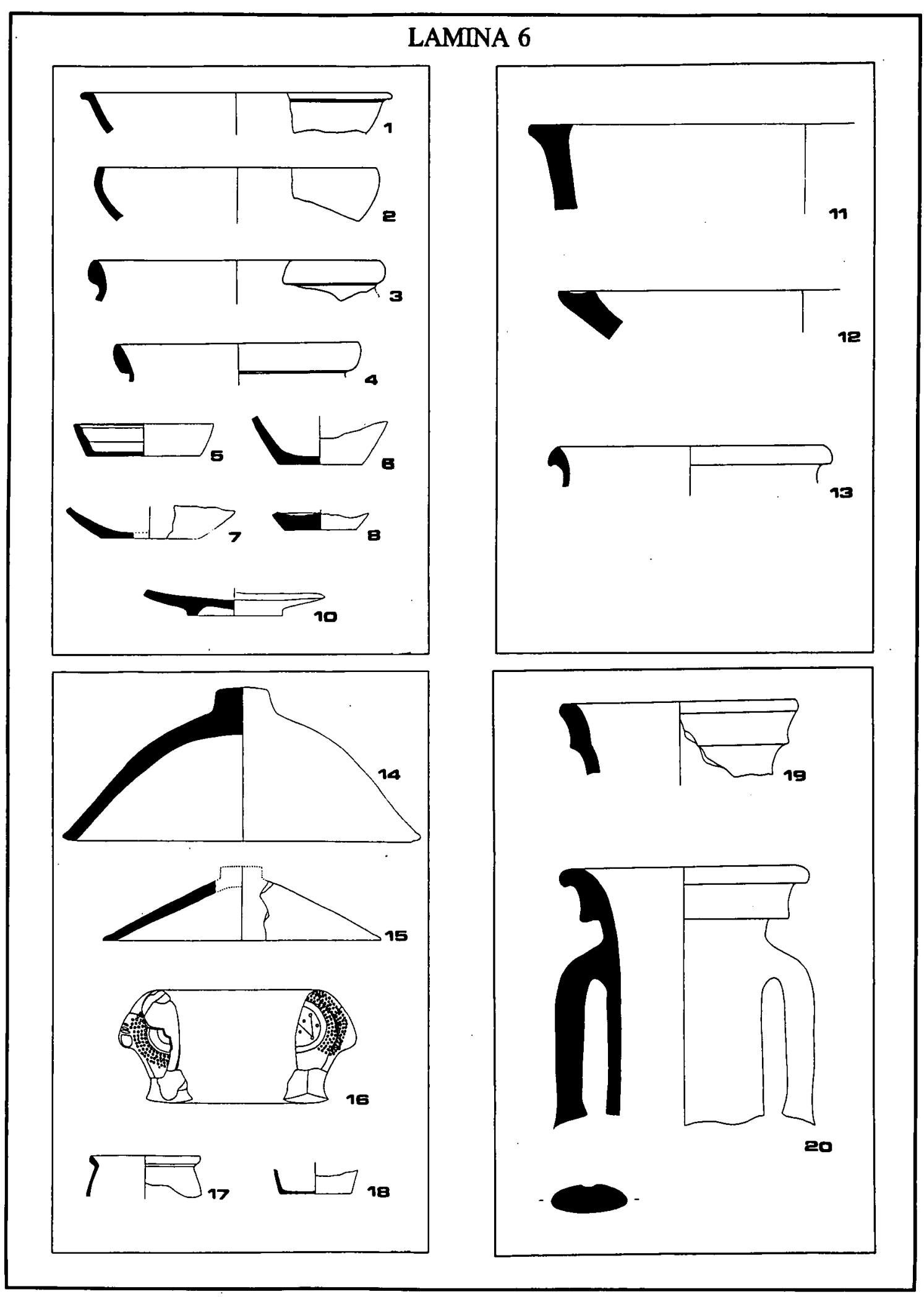




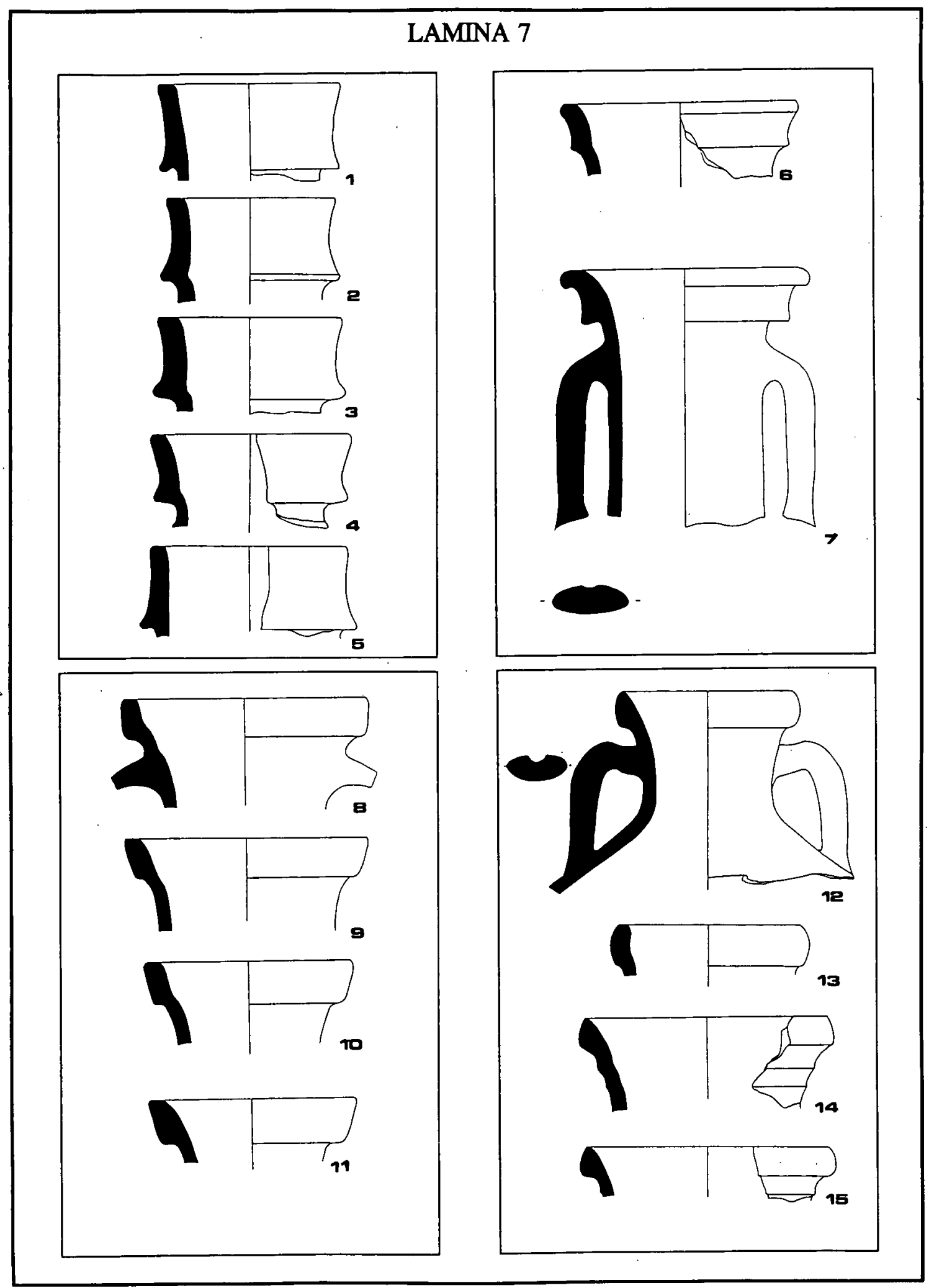




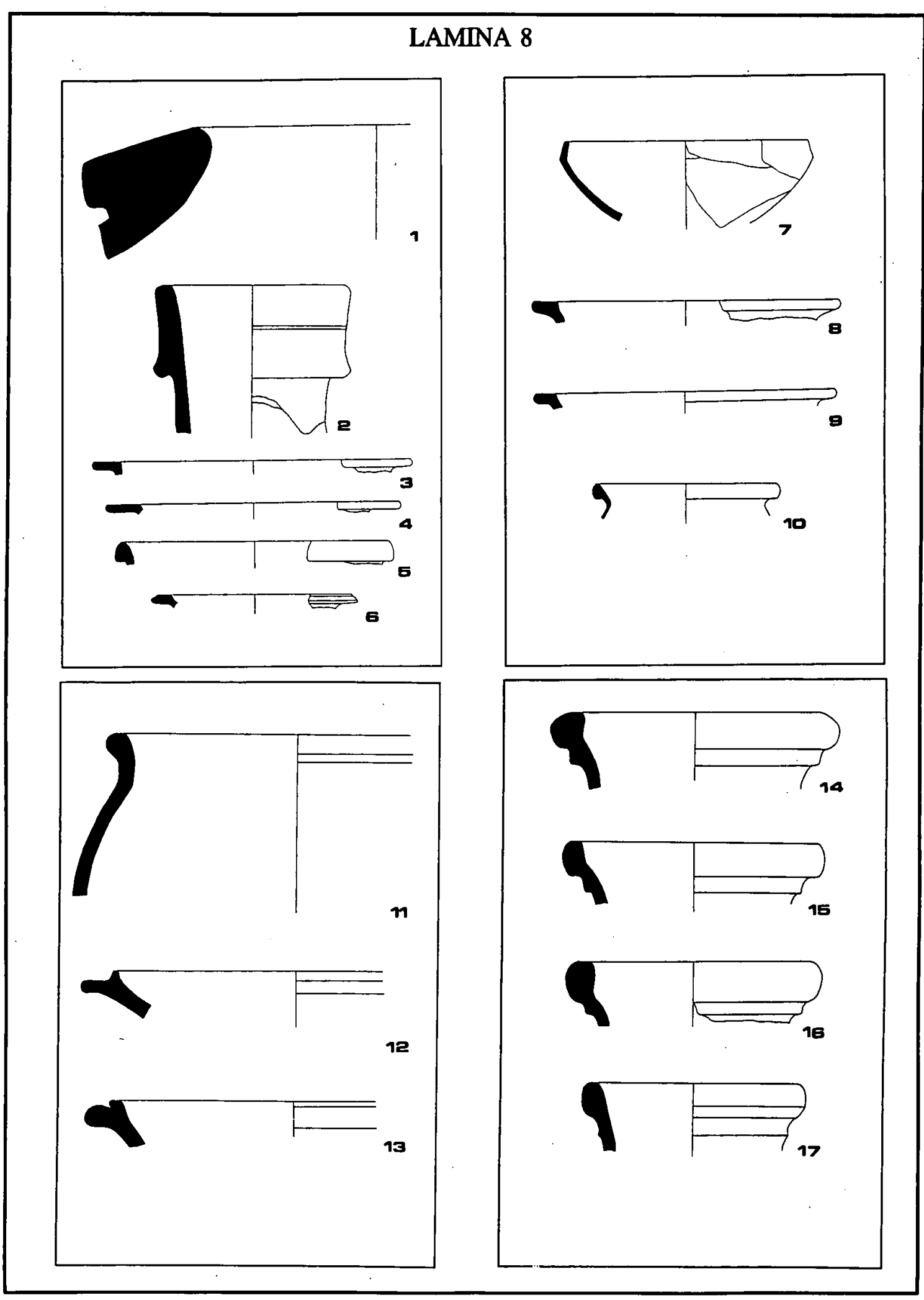




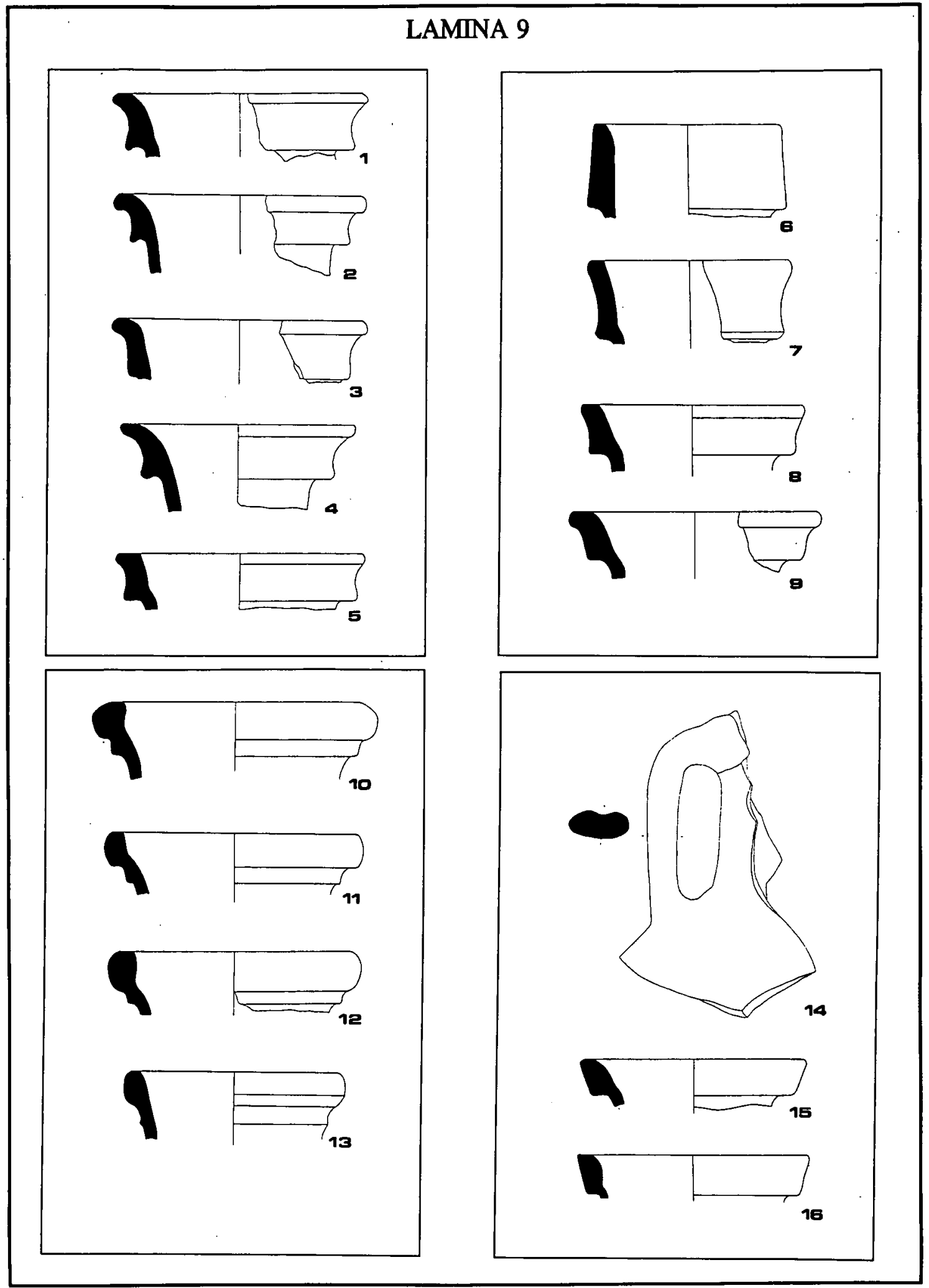




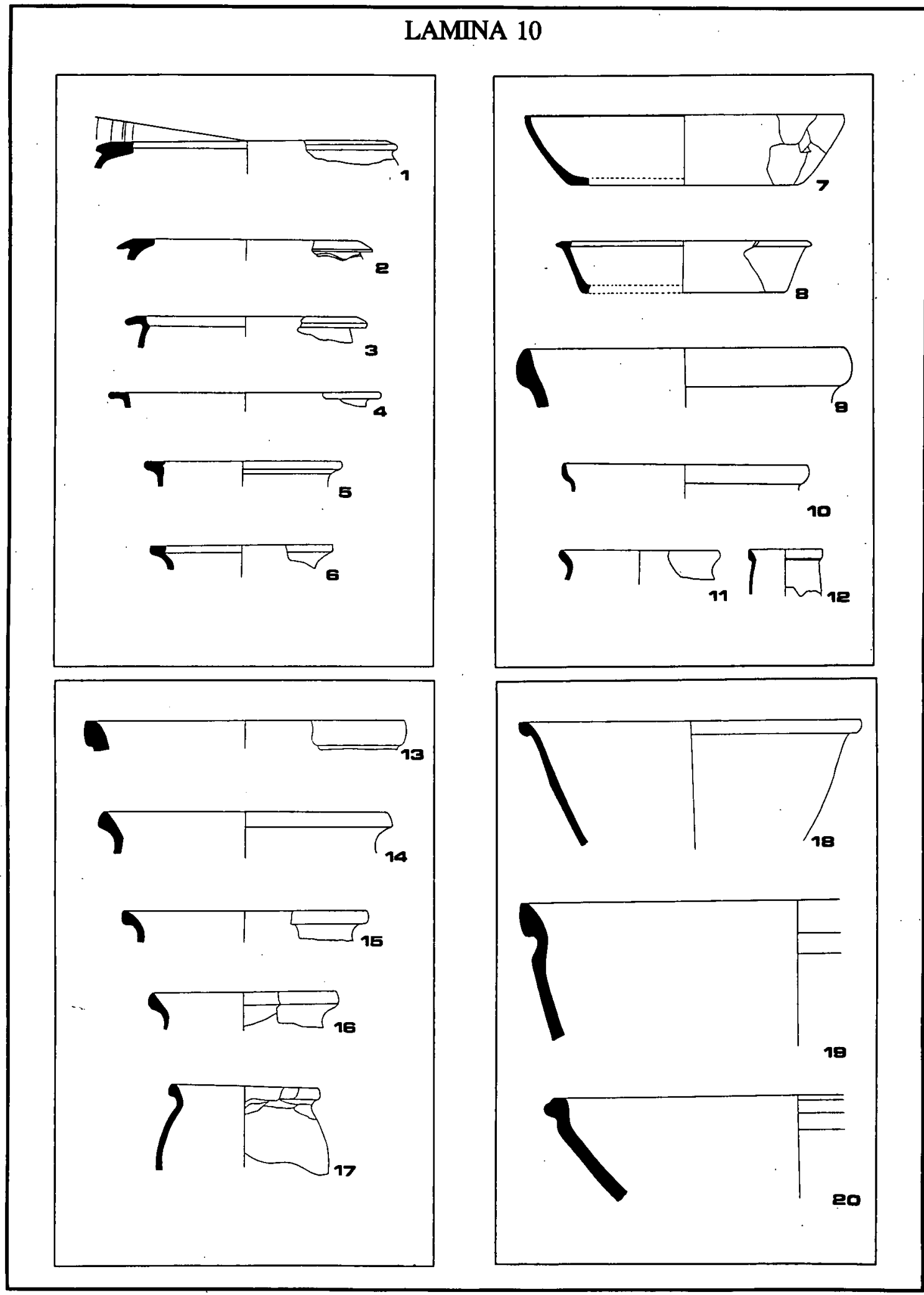

